\title{
Comparison of nine common coffee extraction methods: instrumental and sensory analysis
}

\author{
Alexia N. Gloess • Barbara Schönbächler • Babette Klopprogge • \\ Lucio D‘Ambrosio - Karin Chatelain • Annette Bongartz • \\ André Strittmatter · Markus Rast · Chahan Yeretzian
}

Received: 5 June 2012/Revised: 8 January 2013/ Accepted: 10 January 2013/Published online: 30 January 2013

(C) The Author(s) 2013. This article is published with open access at Springerlink.com

\begin{abstract}
The preparation of a cup of coffee may vary between countries, cultures and individuals. Here, an analysis of nine different extraction methods is presented regarding analytical and sensory aspects for four espressi and five lunghi. This comprised espresso and lungo from a semi-automatic coffee machine, espresso and lungo from a fully automatic coffee machine, espresso from a singleserve capsule system, mocha made with a percolator, lungo prepared with French Press extraction, filter coffee and lungo extracted with a Bayreuth coffee machine. Analytical measurements included headspace analysis with HS SPME GC/MS, acidity (pH), titratable acidity, content of fatty acids, total solids, refractive indices (expressed in ${ }^{\circ}$ Brix), caffeine and chlorogenic acids content with HPLC. Sensory analysis included visual, aroma, flavor and textural attributes as well as aftersensation. The technical differences in the extraction methods led to a higher concentration of the respective quantities in the espressi than in the lunghi. Regarding the contents per cup of coffee, the
\end{abstract}

Electronic supplementary material The online version of this article (doi:10.1007/s00217-013-1917-x) contains supplementary material, which is available to authorized users.

A. N. Gloess $(\square) \cdot$ B. Schönbächler · B. Klopprogge ·

L. D‘Ambrosio - C. Yeretzian

School of Life Sciences and Facility Management, Institute of Chemistry and Biological Chemistry, Zurich University of Applied Sciences, 8820 Wädenswil, Switzerland e-mail: alexia.gloess@zhaw.ch

K. Chatelain · A. Bongartz

School of Life Sciences and Facility Management, Institute of Food and Beverage Innovation, Zurich University of Applied Sciences, 8820 Wädenswil, Switzerland

A. Strittmatter - M. Rast

Rast Kaffee AG, 6031 Ebikon, Switzerland lunghi generally had a higher content than the espressi. The extraction efficiency of the respective compounds was mainly driven by their solubility in water. A higher amount of water, as in the extraction of a lungo, generally led to higher extraction efficiency. Comparing analytical data with sensory profiles, the following positive correlations were found total solids $\leftrightarrow$ texture/body, headspace intensity $\leftrightarrow$ aroma intensity, concentrations of caffeine/chlorogenic acids $\leftrightarrow$ bitterness and astringency.

Keywords Coffee brew - Extraction - Sensory analysis . Chlorogenic acids - Caffeine $\cdot$ Headspace analysis .

Acidity $\cdot$ Fatty acids

\section{Introduction}

Since the discovery of coffee as a beverage prepared from the extract of roasted coffee beans around the fifteenth century, its popularity has quickly spread around the world to become one of the most popular beverages of modern society. During the same period, numerous coffee brewing and extraction methods were introduced, depending on geographic, cultural and social context as well as on personal preferences [1, 2]. Extraction methods are generally characterized by extraction pressure, the extraction process and tool, and the volume of the extract/cup. Another typical distinction made in Western societies is between an espresso and a lungo. Espresso is a concentrated beverage of $20 \mathrm{ml}$ to $40 \mathrm{ml}$, brewed by forcing hot water at high pressure (up to 19 bars) through finely ground coffee and made for immediate consumption. In contrast, a lungo is a less intense beverage characterized by a larger cup size (100 $\mathrm{ml}$ up to $250 \mathrm{ml}$, depending on cultural habits) and often consumed with milk or cream. There are many ways 
of preparing a lungo: (i) similar to an espresso, extracted under high pressure, (ii) by pouring hot water on ground coffee followed by a form of filtering or (iii) by boiling the water/coffee mixture for a distinct period of time. More recently, single-serve coffee systems have gained in popularity.

Consumer preferences for a particular type of coffee preparation mode may be influenced by various factors such as culture, lifestyle, social and working environment, everyday habits and financial considerations and of course also by flavor preferences [1, 2]. More recently, consumer choices have also been affected by information on the chemical composition of various types of coffee and the potential impact of specific components on our health and well-being.

In the last few decades, intense research on coffee has expanded our knowledge of the chemical, sensory and health-related aspects of coffee along the whole value chain, from the bean to the cup. Furthermore, a few studies have been published on specific modes of coffee extraction, in particular on espresso and filter coffee. However, studies comparing a wide range of popular coffee extraction methods with respect to chemical and sensory aspects are rare. The most extensive studies of this type were carried out by López-Galilea et al. [3, 4] and Peters [5]. The former focused mainly on the antioxidant capacity of different brews, namely filter coffee, plunger extraction, mocha extraction and extraction using an espresso machine. Peters studied dripfilter coffee, the mocha and napolitana system as well as French Press, percolator and boiled coffee with respect to their content of dry solids, caffeine, chlorogenic acids and non-aromatic acids using different types of coffee for the different extraction methods and did not perform sensory analysis of the different coffee brews.

In this study, we have examined nine extraction methods-four espressi and five lunghi-using instrumental and sensory tools to compare a wide range of popular coffee extraction methods with respect to chemical and sensory aspects. To the best of our knowledge, there is so far no study comprising such a big number of extraction methods evaluated under instrumental and sensory aspects. Giving a comprehensive chemical and sensory overview of the most common coffee extraction methods in Europe of nowadays, this study closes the gap in the literature, focusing mostly either on analytics or on sensory results, or comparing only two to three types of extraction methods. In addition, it reveals that there is not $a$ best extraction method, but every extraction method has its own characteristics. Beside this characterization of nine different extraction methods regarding their chemical composition as well as their sensory characteristics, this study is also aiming at revealing correlations between instrumentally measured parameters with sensory-evaluated attributes.
The parameters were chosen so that many important quality criteria for a good cup of coffee were covered. They are the following: The first impression of a cup of coffee is visual related to the crema, the color and the volume. The next impression is the aroma perceived ortho-nasally and measured via analysis of the headspace of the coffee brew [6-8]. More than 1,000 volatile organic compounds (VOCs) have so far been identified in the gas phase of coffee, yet only a fraction is odor active, and around 20 are key aroma compounds, that is, are relevant for a typical coffee aroma [9-11].

The next impression is the flavor, which corresponds to a combination of retro-nasal aroma impression and taste. A well-balanced acidity interacting with a fruity and roasty note, rounded by a slight, coffee-like bitterness, is often considered to be a good coffee flavor. In this overall impression, the acidity of the brew is a particularly important criterion for a good cup of coffee. One part of this study was to evaluate the influence of the extraction method on the acidity of the brews. From an instrumental point of view, we measured the $\mathrm{pH}$ value as well as the titratable acidity up to a $\mathrm{pH}$ of 6.6 , corresponding approximately to the $\mathrm{pH}$ in the mouth when drinking coffee, and up to a $\mathrm{pH}$ of 8.0 , where the weaker organic acids in the coffee brew are also covered [12].

The body, also called mouth-feeling or texture, is a further important sensory descriptor for coffee. From an instrumental perspective, it is often related to the total solids and occasionally also linked to fat or fatty acid content. Furthermore, for sustained sensation at the end of a sip, the finishing should be well balanced between the aroma, acidity, bitterness and astringency. The contents of caffeine and chlorogenic acids are said to be important factors for the salubriousness of coffee. The latter are degrading during the roasting process [2, 13-17]. However, they are known to be important antioxidants and are active even at concentrations as low as $10 \mu \mathrm{g} / \mathrm{ml}$ of 5-CQA [15, 18]. However, at higher concentrations, the chlorogenic acids are said to cause acid reflux symptoms, together with other compounds [15]. Both caffeine and chlorogenic acids are often mentioned in conjunction with bitterness. Astringency may correlate to the concentration of chlorogenic acids in the brew [19], although the molecules causing the astringent feeling may not be those of chlorogenic acids [20].

\section{Materials and methods}

\section{General}

The same coffee was used for all extractions (Guatemala Antigua LA CEIBA), except for the single-serve capsules (Nespresso/Arpeggio capsules). Green beans were roasted 
at RAST Kaffee, Ebikon, Switzerland, to a roast degree of Pt 80 (Colorette, 3b, PROBAT-WERKE, Emmerich am Rhein, Germany) for espresso and Pt 86 for lungo, packed in 1-kg airtight bags (laminate with a metallized film, with valve) and stored at room temperature before use (1-2 weeks). The different roast degrees chosen here may imply a different composition of chlorogenic acids, but they are closer to a typical consumer's situation. Local tap water was mixed with filtered water (PURITY 600 Quell ST, BRITA Professional, Taunusstein, Germany) to adjust the extraction water to $4-6^{\circ} \mathrm{dH}$ (German water hardness). The milling degree as well as the amount of ground coffee were optimized for each brewing type and are described in the following. For grinding, an Espresso Grinder (KED 640, Ditting, Bachenbülach, Switzerland, milling degree $1=$ finest to $8=$ coarse) as well as a retail grinder (KR 805, Ditting, Bachenbülach, Switzerland, milling degree $1=$ finest to $8=$ coarse) were used. The coffee was always freshly ground before coffee extraction (except for the single-serve capsule system). The particle size distributions of the coffee powder ground on the Ditting grinders are given in Analytical Techniques-Particle size of ground coffee. For the coffee ground on the fully automatic coffee machine (with integrated grinder), and the preground coffee for the single-serve capsule system, no particle size distribution was measured. The milling degree of the fully automatic coffee machine was set by the service technician to optimize the extraction time. The main extraction parameters are summarized in Table 1. These were optimized for each brewing method, keeping as many parameters as possible constant while trying to reflect a typical extraction of coffee of a consumer. For each brewing type, the first extraction was discarded. Three samples per extraction type were prepared, and each was analyzed in triplicate. Most samples were measured on two different days.

\section{Coffee extraction}

Nine different extraction methods were examined, comprising four espressi and five lunghi.

Espresso from semi-automatic machine-(DE) A Dalla Corte Evolution 20.03 with two brewing units was used (Rogalla-Dalla Corte Schweiz, Switzerland). Three coffee samples were prepared, each combining five freshly brewed double espressi, resulting in $300 \mathrm{ml}$ per sample.

Lungo from semi-automatic machine-(DL) A Dalla Corte Evolution 20.03 was used (as above). Per sample, two extractions were combined to $480 \mathrm{ml}$.

Espresso from fully automatic machine-(SE) The settings of the fully automatic coffee machine Schaerer Coffee Celebration BC (Schaerer, Switzerland) were chosen so that per brew two espressi à $30 \mathrm{ml}$ were extracted in $25.3 \pm 0.7 \mathrm{~s}(n=15,95 \%)$ at a pressure of 8.25 bar and
Table 1 Details of the extractions: the extraction method (for abbreviations - see text), the roast degree in Pt (measured with Colorette $3 b$, Probat), the milling degree and the amount of ground coffee per extraction in grams, the volume of water per cup or jug in milliliters, the extraction time in seconds, the extraction temperature in degrees centigrade, and the extraction pressure in bar are given

\begin{tabular}{|c|c|c|c|c|c|c|c|}
\hline $\begin{array}{l}\text { Extraction } \\
\text { method }\end{array}$ & $\begin{array}{l}\text { Roast } \\
\text { degree }\end{array}$ & Milling degree & & $\begin{array}{l}\text { Ground coffee } \\
\text { per extraction }\end{array}$ & $\begin{array}{l}\text { Volume of extract } \\
\text { per cup or jug }\end{array}$ & $\begin{array}{l}\text { Extraction } \\
\text { time }\end{array}$ & $\begin{array}{l}\text { Extraction temperature } \\
\text { extraction pressure }\end{array}$ \\
\hline & $\mathrm{Pt}$ & KED 640 & KR 805 & $\mathrm{~g}$ & $\mathrm{ml}$ & $\mathrm{s}$ & ${ }^{\circ} \mathrm{C}$, bar \\
\hline$\overline{\mathrm{DE}}$ & 80 & $\begin{array}{l}3.0 \text { (DE1) between } 2.5 \text { and } \\
2.75 \text { (DE2, DE3) }\end{array}$ & & $16.01 \pm 0.01^{\mathrm{a}}$ & $2 \times 30$ & $28.7 \pm 0.2^{\mathrm{a}}$ & $92{ }^{\circ} \mathrm{C}, 9$ bar \\
\hline DL & 86 & 7.25 (DL1) 7.5 (DL2, DL3) & & $16.01 \pm 0.01^{\mathrm{a}}$ & $2 \times 120$ & $37.2 \pm 0.3^{\mathrm{a}}$ & $92{ }^{\circ} \mathrm{C}, 9$ bar \\
\hline SE & 80 & $-^{\mathrm{b}}$ & - & $16.0 \pm 0.6^{\mathrm{c}}$ & $2 \times 30$ & $25.3 \pm 0.3^{\mathrm{a}}$ & $90{ }^{\circ} \mathrm{C}^{\mathrm{d}}, 8.25$ bar \\
\hline SL & 86 & $-{ }^{b}$ & - & $16.0 \pm 0.6^{\mathrm{c}}$ & $2 \times 120$ & $35.3 \pm 0.1^{\mathrm{a}}$ & $90^{\circ} \mathrm{C}^{\mathrm{d}}, 7.5$ bar \\
\hline $\mathrm{Bia}$ & 86 & Between 2.5 and 2.75 & & $7.5 \pm 0.1^{\mathrm{a}}$ & 110 & $224 \pm 12^{\mathrm{a}}$ & n.n. \\
\hline $\mathrm{NE}$ & - & $-{ }^{b}$ & - & $5.5 \pm 1.1^{\mathrm{a}}$ & 30 & $24 \pm 2^{\mathrm{a}}$ & n.n./19 bar ${ }^{\mathrm{e}}$ \\
\hline $\mathrm{F}$ & 80 & & 8.0 & $100.02 \pm 0.03^{\mathrm{a}}$ & 1,800 & $348 \pm 2^{\mathrm{a}}$ & ca. $90{ }^{\circ} \mathrm{C}, 1$ bar \\
\hline KK & 80 & & 8.0 & $27.500 \pm 0.003^{\mathrm{a}}$ & 500 & $370 \pm 10^{\mathrm{a}}$ & ca. $90^{\circ} \mathrm{C}, 1$ bar \\
\hline Bo & 80 & & 8.0 & $27.493 \pm 0.003^{\mathrm{a}}$ & 500 & $240 \pm 2^{a}$ & ca. $90^{\circ} \mathrm{C}, 1$ bar \\
\hline
\end{tabular}

\footnotetext{
a Standard deviation of the mean

${ }^{b}$ Information not provided by the manufacturer. For SE and SL, the milling degree was set by the service technician to optimize the extraction time

c The amount of ground coffee was regulated in the initial setting of the machine, together with the service technician; the error is an estimated value

${ }^{\mathrm{d}}$ Corresponds to the temperature of the boiler. The exact extraction temperature is not defined

${ }^{\mathrm{e}}$ Information provided by the manufacturer
} 
a temperature of ca. $90{ }^{\circ} \mathrm{C}$. The amount of ground coffee per $30 \mathrm{ml}$ was about $8 \mathrm{~g}$ Guatemala Pt 80 . Five extracts were combined, resulting in $300 \mathrm{ml}$ per sample.

Lungo from fully automatic machine-(SL) was brewed on the above-mentioned Schaerer Coffee Celebration BC. At an extraction temperature of circa $90{ }^{\circ} \mathrm{C}$ and a pressure of $7.5 \mathrm{bar}$, two cups à $120 \mathrm{ml}$ were extracted in $35.3 \mathrm{~s} \pm 0.2 \mathrm{~s}(n=6,95 \%)$ (circa $8 \mathrm{~g}$ roast and ground Pt 86 per cup). For each sample, two extracts were combined.

Espresso-Nespresso (NE) samples were prepared from 10 espresso capsules (circa $30 \mathrm{ml}$ extracts) of the variety "Arpeggio" (Nestlé Nespresso, Switzerland) on a Nespresso machine (Turmix TX 170 CitiZ Steel Gray, DKB Household Switzerland AG, Switzerland).

Espresso-Bialetti (Bia) An espresso maker, Moka Express, designed for three cups (Bialetti, Coccaglio, Italy) was used. Three extracts à $110 \mathrm{ml}$ were combined per sample.

Lungo-French Press (Bo) extraction was prepared with a double-wall coffee maker Shin Bistro (Bodum, Switzerland).

Lungo-Karlsbader Kanne (KK) was extracted on a preheated Bayreuth coffee maker using the traditional Karlsbad method (Erste Bayreuther Porzellanfabrik Walküre Siegmund Paul Meyer GmbH, Germany). For brewing, $500 \mathrm{ml}$ of boiled water (ca. $90{ }^{\circ} \mathrm{C}$ ) was poured in small portions onto the ground coffee and reheated in between.

Lungo-Filter Coffee $(F)$ was brewed using a paper filter and a coffee machine from Hapag Aarau (HAPAG AARAU Mod. A140, HAPAG AG, Switzerland).

\section{Analytical techniques}

Total solids A total of $10 \mathrm{~g}$ of coffee extract was dried at $105{ }^{\circ} \mathrm{C}$ until constant weight (less than $\pm 0.5 \mathrm{mg}$ ). The refractive index of the coffee brews was measured at $20{ }^{\circ} \mathrm{C}$ (refractometer AB-1, Krüss, Germany) and converted to ${ }^{\circ}$ Brix values according to [21].

$\mathrm{pH}$ and titration The $\mathrm{pH}$ of each sample was measured at $20{ }^{\circ} \mathrm{C}$. A total of $40 \mathrm{ml}$ of coffee brew was titrated with $0.1 \mathrm{M} \mathrm{NaOH}$ at $20{ }^{\circ} \mathrm{C}$ to (i) a pH of 6.6 and (ii) a pH of 8.0 (Titrando 809, Metrohm, Switzerland).

Headspace-SPME-GC/MS A total of $10 \mathrm{ml}$ of coffee extract was analyzed immediately after preparation with headspace-solid-phase micro-extraction-gas chromatography/mass spectrometry (HS SPME-GC/MS). A polydimethyl-siloxane/divinylbenzene (PDMS/DVB) SPME fiber with a $65-\mu \mathrm{m}$-thick film (Supelco, Sigma-Aldrich Chemie GmbH, Switzerland) and a DB-WAX (30 $\mathrm{m} \times$ $250 \mu \mathrm{m} \times 0.25 \mu \mathrm{m}$ ) column (Agilent Technologies, Switzerland) were used. The time temperature profile was chosen as follows. SPME parameters (Gerstel, Switzerland): incubation: $4 \mathrm{~min}$ at $50{ }^{\circ} \mathrm{C}$, agitating at $250 \mathrm{rpm}$; extraction time: $7 \mathrm{~min}$ at $50{ }^{\circ} \mathrm{C}$; desorption time: $5 \mathrm{~min}$ at $240{ }^{\circ} \mathrm{C}$; GC/MS parameters (7890/5975 N, Agilent Technologies, Switzerland): $35{ }^{\circ} \mathrm{C}$ for $1 \mathrm{~min}$, then $4{ }^{\circ} \mathrm{C} / \mathrm{min}$ to $100{ }^{\circ} \mathrm{C}$ for $10 \mathrm{~min}$, followed by $30^{\circ} \mathrm{C} / \mathrm{min}$ to $130^{\circ} \mathrm{C}$ for $8 \mathrm{~min}$, and finally $6{ }^{\circ} \mathrm{C} / \mathrm{min}$ to $220^{\circ} \mathrm{C}$ for $5 \mathrm{~min}$; split less mode; flow $1 \mathrm{ml} / \mathrm{min}$; EI source $70 \mathrm{eV}, 230^{\circ} \mathrm{C}$; detector $150{ }^{\circ} \mathrm{C}$. For data analysis, the software MSD Chemstation (Version G1701 EA E.02.00.493, Agilent Technologies, Switzerland) and the database NIST08 were used. Chemical identification was performed via the respective mass spectrum and retention time. A typical chromatogram is shown in Fig. 1. More than 100 compounds were identified, and 38 molecules contributing to the aroma of coffee were chosen to evaluate the headspace of the respective coffee brew extraction methods (see Electronic Supplementary Material, Supp. Table 1) [9-11, 22-29]. Their integrated intensities are summed up to the total headspace intensity which is compared here for the different extraction types.

Analysis of fatty acids The coffee extract was transesterificated according to the method 269.1 in the Schweizerisches Lebensmittelbuch [30]. In brief, $15 \mathrm{~g}$ of coffee extract and $500 \mu \mathrm{l}$ recovery standard $(50 \mathrm{mg}$ glyceryl tridecanoat in $10 \mathrm{ml}$ dioxan) were adsorbed on an Extrelut ${ }^{\circledR}$ NT 20 column (VWR International AG, Switzerland). With diethyl ether (Sigma-Aldrich Chemie GmbH, Switzerland), the nonpolar compounds were washed out. Diethylether was evaporated and $4.5 \mathrm{ml}$ dioxan (SigmaAldrich Chemie GmbH, Switzerland) and $500 \mu l$ internal standard (50 mg methyl nonanoate, $50 \mathrm{mg}$ glyceryl triundecanoate and $50 \mathrm{mg}$ tetradecen in $10 \mathrm{ml}$ dioxan) were added to the residuum and mixed with $5 \mathrm{ml}$ of $5 \%$ sodium methylate-methanol solution. After $1 \mathrm{~min}$, the transesterificated coffee oil was extracted with $15 \mathrm{ml}$ heptane and $10 \mathrm{ml}$ aqueous disodium hydrogen citrate solution (SigmaAldrich, Switzerland).

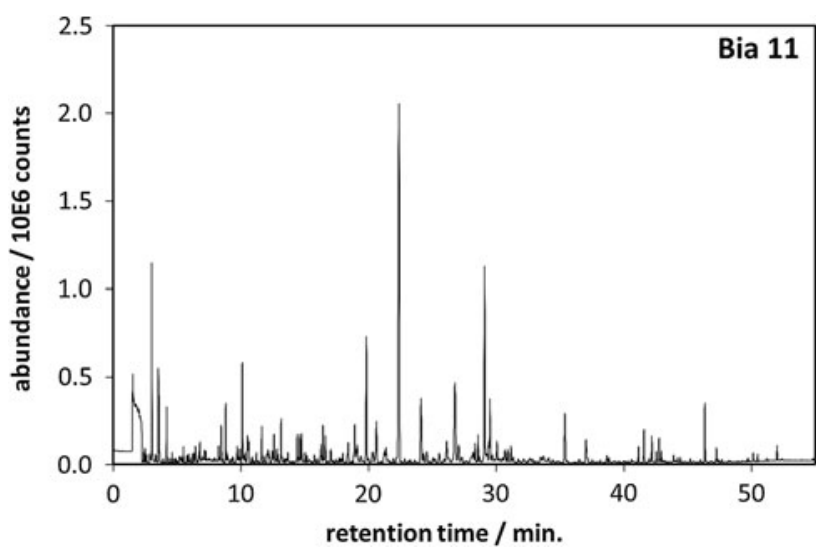

Fig. 1 HS SPME GC/MS chromatogram of Bia11 as an example of a typical chromatogram. The intensity in abundance $\left(10^{6} \times\right.$ total ion current) is plotted against the retention time in minutes 
The resulting fatty acid methyl esters (FAME) were analyzed with GC/MS, a typical chromatogram is shown in Fig. 2. A total of $1 \mu \mathrm{l}$ of the organic phase was injected into the GC/MS (Agilent 6890 (GC), 7683 (injector), 5973 N (MS), Agilent Technologies, Switzerland). GC/MS parameters: Injection was performed with a split of 5.2:1 at $250{ }^{\circ} \mathrm{C}$. The oven was kept at $70{ }^{\circ} \mathrm{C}$ for 2 min and then heated with $6{ }^{\circ} \mathrm{C} / \mathrm{min}$ to $240{ }^{\circ} \mathrm{C}$ and kept for $10 \mathrm{~min}$ at $240{ }^{\circ} \mathrm{C}$. A capillary column HP-FFAP $(30 \mathrm{~m} \times 250 \mu \mathrm{m}$ $\times 0.25 \mu \mathrm{m}$, Agilent Technologies, Switzerland) was chosen with a constant helium flow of $2 \mathrm{ml} / \mathrm{min}$. For data analysis, the software MSD Chemstation (Version D.03.00.611, Agilent Technologies, Switzerland) and the database NIST08 were used.

This method analyzes only the esterified fatty acids in the coffee extracts, and not the free fatty acids, as they are most probably retained on the Extrelut ${ }^{\circledR}$ NT 20 column. Since most of the fatty acids in coffee are esterified, the majority as triglycerides and a few as diterpene esters or sterol esters [31-33], this analysis closely reflects the composition of fatty acids in the coffee extracts.

Chlorogenic acids and caffeine content $2 \mathrm{~g}$ coffee extract, $500 \mu$ l Carrez I (30\% aqueous $\mathrm{ZnSO}_{4}$ solution),

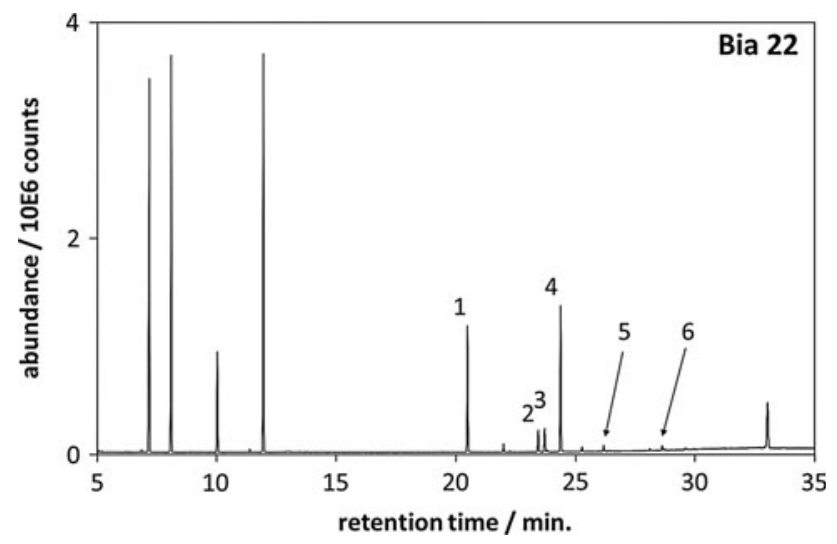

Fig. 2 GC/MS chromatogram of the FAME analysis of Bia22 as an example of a typical chromatogram. The intensity in abundance $\left(10^{6} \times\right.$ total ion current) is plotted against the retention time in minutes. $1 \mathrm{C} 18$ octadecanoic acid methyl ester, $2 \mathrm{C} 18: 1$ octadecenoic acid methyl ester, $3 \mathrm{C} 18: 2$ octadecadienoic acid methyl ester, $4 \mathrm{C} 18: 3$ octadecatrienoic acid methyl ester, 5 C20 eicosanoic acid methyl ester and 6 C22 docosanoic acid methyl ester
$500 \mu \mathrm{l}$ Carrez II (15\% aqueous potassium hexacyano (II) ferrate trihydrate) and $500 \mu \mathrm{l}$ methanol were diluted with distilled water up to $25 \mathrm{ml}$ and filtered with filter paper (Faltenfilter LS 171/2, D $=150 \mathrm{~mm}$, Schleicher \& Schuell, Germany) and a syringe filter (Chromafil Xtra PET-45/ 25, Macherey-Nagel, Switzerland). Quantitative analyses were performed using an Agilent Series 1200 HPLC, equipped with an Agilent Eclipse Plus C18 $1.8 \mu$ Column $\left(100 \mathrm{~mm} \times 2.1 \mathrm{~mm}\right.$ i.d., thermostat at $\left.20^{\circ} \mathrm{C}\right)$ and a diode array detector. Mobile Phase A was water (containing $0.1 \%$ formic acid) and mobile phase B was acetonitrile (containing $0.1 \%$ formic acid). The gradient mode is 1 min with $5 \%$ mobile phase B, then 10 min with $25 \%$ of $\mathrm{B}$ and finally $50 \%$ of B for $20 \mathrm{~min}$. The flow rate was $0.35 \mathrm{ml} / \mathrm{min}$. The detector was set at $325 \mathrm{~nm}$ for chlorogenic acids and $272 \mathrm{~nm}$ for caffeine. The injection volume was $3 \mu \mathrm{l}$. Substances were identified by comparing their retention times to those of the respective standards. Typical chromatograms are shown in Fig. 3. Concentrations of 3-CQA, 5-CQA and caffeine were calculated using the regression equation of external standards and corrected with the recovery rate. No commercial standard was available for 4-CQA while conducting these measurement; hence, it was not quantified here. 5- $O$-caffeoyl quinic acid (5-CQA) was obtained from Chengdu Biopurify Phytochemicals, China, caffeine from Sigma-Aldrich Chemie, Switzerland, and 3-O-caffeoyl quinic acid (3-CQA) from Acros Chemicals, Switzerland.

Particle size of ground coffee The particle size distributions of the respective milling degrees 3 and 7 of Espresso Grinder KED 640 (Ditting, Switzerland) and of milling degree 8 of the retail grinder KR 805 (Ditting, Switzerland) were analyzed with laser diffraction at DELICA AG (Switzerland). The results were as follows: KED-3: $400 \mu \mathrm{m}$ at maximum of size distribution (max), $220 \mu \mathrm{m}$ at the full width of half-maximum (FWHM); KED-7: $600 \mu \mathrm{m} \quad \max , \quad 250 \mu \mathrm{m}$ FWHM; KR805-8: 1,000-1,025 $\mu \mathrm{m} \max , 280 \mu \mathrm{m}$ FWHM.

Sensory evaluation was performed by a trained sensory panel of seven panelists, in accordance with DIN 10967-2 (profiling based on consensus). The temperature and humidity conditions as well as the serving temperatures of
Fig. 3 Typical HPLC chromatograms of a caffeine at $272 \mathrm{~nm}$ and $\mathbf{b}$ chlorogenic acids at $325 \mathrm{~nm}$ in a coffee extract. The detector response in absorption units (mAU) is plotted against the elution time in minutes. 1 Caffeine, 2

5-CQA, 3 3-CQA
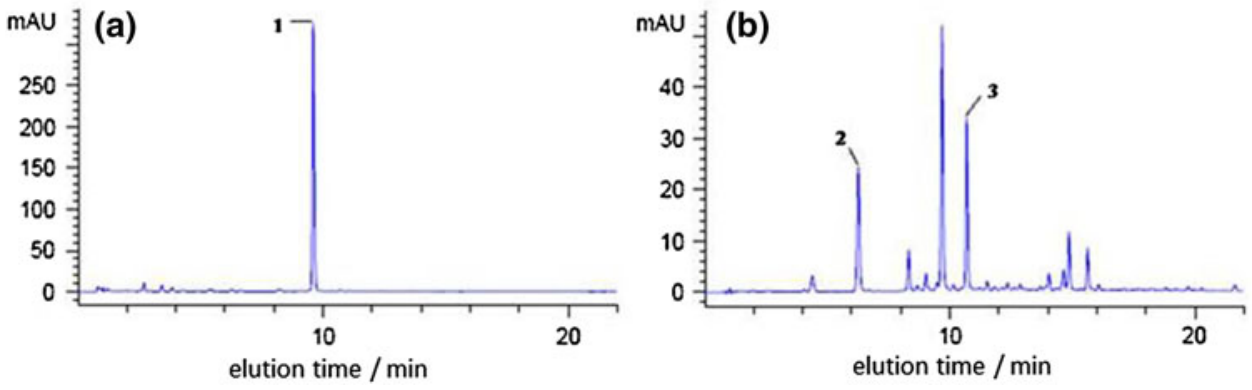
Table 2 Serving conditions of the extracts on the two different testing days, including the room temperature in degrees centigrade $\left({ }^{\circ} \mathrm{C}\right)$, the relative humidity in percent (\%) as well as the serving temperature in degrees centigrade $\left({ }^{\circ} \mathrm{C}\right)$ for the respective extraction methods

\begin{tabular}{|c|c|c|c|}
\hline & Day 1 & & Day 2 \\
\hline $\begin{array}{l}\text { Room } \\
\text { temperature }\end{array}$ & $21.5^{\circ} \mathrm{C}$ & $\begin{array}{l}\text { Room } \\
\text { temperature }\end{array}$ & $21.6^{\circ} \mathrm{C}$ \\
\hline $\begin{array}{l}\text { Relative } \\
\text { humidity }\end{array}$ & $43.2 \%$ & $\begin{array}{l}\text { Relative } \\
\text { humidity }\end{array}$ & $35.8 \%$ \\
\hline $\begin{array}{c}\text { Extraction } \\
\text { method }\end{array}$ & $\begin{array}{l}\text { Serving } \\
\text { temperature }\end{array}$ & $\begin{array}{c}\text { Extraction } \\
\text { method }\end{array}$ & $\begin{array}{l}\text { Serving } \\
\text { temperature }\end{array}$ \\
\hline KK & $60.9^{\circ} \mathrm{C}$ & $\mathrm{F}$ & $63.9^{\circ} \mathrm{C}$ \\
\hline Bo & $69.9^{\circ} \mathrm{C}$ & DL & $67.9^{\circ} \mathrm{C}$ \\
\hline SL & $69.6^{\circ} \mathrm{C}$ & $\mathrm{DE}$ & $64.2^{\circ} \mathrm{C}$ \\
\hline SE & $63.9^{\circ} \mathrm{C}$ & $\mathrm{NE}$ & $68.3^{\circ} \mathrm{C}$ \\
\hline Bia & $68.1^{\circ} \mathrm{C}$ & & \\
\hline
\end{tabular}

Table 3 Sensory attributes in the categories: optic of crema, aroma, flavor, texture and aftersensation

\begin{tabular}{lllll}
\hline $\begin{array}{l}\text { Optic of } \\
\text { crema }\end{array}$ & Aroma & Flavor & Texture & Aftersensation \\
\hline Quantity & $\begin{array}{c}\text { Overall } \\
\text { intensity }\end{array}$ & Fruity & Body & Aroma \\
Fineness & Fruity & $\begin{array}{c}\text { Cereal/ } \\
\text { nuts }\end{array}$ & Acidity \\
Color & Cereal/nuts & $\begin{array}{c}\text { Roasty } \\
\text { Sweetness }\end{array}$ & Bitterness \\
& Roasty & Astringency \\
& & Acidity & \\
& & Bitterness & \\
\hline
\end{tabular}

the extractions are given in Table 2. Each extraction method was analyzed in duplicate. The coffee was prepared fresh before analysis. The serving temperatures were measured on randomly chosen cups of coffee with a digital thermometer (type $106,-50{ }^{\circ} \mathrm{C}$ to $+275{ }^{\circ} \mathrm{C}$, Testo $\mathrm{AG}$, Switzerland). The differences in the serving temperatures are inherent in the extraction methods. In principle, differences in the serving temperature may influence the sensory perception of, for example, acidity. Eighteen sensory attributes divided into five categories (see Table 3) were evaluated on a scale from " $0=$ not perceivable" to " 5 = very strong." Regarding the sensory attributes acidity and astringency, one has to keep in mind that acidity is a basic taste in the mouth, whereas astringency is a tactile sensation best described by a rough, dry mouth-feeling, evoked by chemical stimuli. The attributes in the flavor correspond to the sensation when the coffee still is in the mouth. The attributes in the aftersensation correspond to the sensation when the coffee is already spit out or swallowed. In the case of the attributes crema-fineness, the scale was " $0=$ rough-porous" to " $5=$ fine-porous," in the case of crema-color, the scale was " $0=$ clear brown" to " $5=$ dark brown," and in the case of crema-quantity, the scale was " $0=$ small amount" to " $5=$ huge amount." To neutralize the panelists' pallets between the tastings of different extracts, water and crackers (Jacob's Cream Crackers) were available.

Principal Component Analysis (PCA) The PCA was performed with the software XLStat (version 2010.4.06). All attributes, chemical or sensory, were included in the PCA, which was calculated based on the Pearson correlation matrix. All data were auto-scaled before use.

\section{Results and discussion}

The purpose of this study was to compare different types of coffee extraction methods and to correlate analytical measurements with sensory evaluation. To the best of our knowledge, this is the first study applying such a large and consistent range of instrumental and sensory methods and covering so wide a range of coffee extraction methods. The nine extraction methods (four espressi and five lunghi) analyzed in this study are the following: a semi- and a fully automatic coffee machine, a single-serve capsule system, mocha made with a percolator, a French Press (also called Plunger Pot), filter coffee (paper filter) and a Bayreuth coffee machine (traditional Karlsbad method). The extraction parameters were optimized for each brewing method to be as close as possible to settings used by consumers while guaranteeing the best possible comparability.

Instrumental results are presented from three perspectives: Firstly, results are presented from the perspective of having a sip of coffee, approximated as a $10-\mathrm{ml}$ volume of coffee brew. This reflects a typical consumer's viewpoint and the situation of sensory evaluation by the panel. Secondly, the content of a full cup of coffee, namely $30 \mathrm{ml}$ for espresso and $120 \mathrm{ml}$ for lungo, is presented, to point out the difference between the concentration of ingredients in a sip of coffee and the total content of ingredients in a whole cup of coffee. In particular, in some medicinal aspects, but also for the sensory perception, it is important to differentiate between the concentration of a specific compound and the total content of a specific compound in a cup of coffee. Thirdly, the extraction efficiency for the various coffee constituents is given. Fourthly, the sensory point of view is presented, before the advantages and shortcomings of the respective extraction types are summarized. Finally, the sensory results are compared to instrumental measurements.

From the instrumental point of view, we analyzed the headspace of the brew by headspace-solidphase microextraction—gas chromatography/mass spectrometry (HS SPME-GC/MS), the acidity ( $\mathrm{pH}$ value), the titratable acidity up to $\mathrm{pH} 6.6$ and $\mathrm{pH} 8.0$, the content of fatty acids 
with GC/MS, the content of total solids (by gravimetry), the ${ }^{\circ}$ Brix value (via refractive index) and the content of caffeine and chlorogenic acids (3-CQA, 3-O-caffeoyl quinic acid and 5-CQA, 5-O-caffeoyl quinic acid) with high-performance liquid chromatography (HPLC). The 4-O-caffeoyl quinic acid (4-CQA) is an important constituent of the coffee brew, also, but for technical reasons, we were not able to quantify 4-CQA in this project (for further details see Materials and Methods).

Sensory analysis included the following attributes: optic of crema (quantity, fineness, color), aroma (overall intensity, and fruity, cereal/nuts and roasty attributes), flavor (fruity, cereal/nuts, and roasty attributes, sweetness, acidity, bitterness), texture (body) and aftersensation, also called "finishing" (aroma, acidity, bitterness, astringency), comprising 18 sensory attributes in total.

\section{Content per sip of coffee}

In Fig. 4, the results with respect of the content of the total solids, the ${ }^{\circ}$ Brix values, the $\mathrm{pH}$ values and the titratable acidity, the results for headspace intensity, fatty acid content, caffeine and chlorogenic acids for the respective extraction methods are given per $10 \mathrm{ml}$ of coffee extract, which corresponds to the amount of coffee brew in one sip. In the Electronic Supplementary Material, this information is given also in table form (Supp. Table 2). In most cases, the espressi show higher concentrations than the lunghi.

Total solids, refractive index and ${ }^{\circ}$ Brix The espressi DE, SE and NE had a content of total solids of above $4 \%$, which is typical for an espresso and considered a prerequisite for a good espresso by barista [2]. Extraction with the Bialetti led to a smaller content of $2.13 \% \pm 0.01 \%$, which is, strictly speaking, too low for an espresso. However, it should be borne in mind that, while this extraction method is generally considered to be an espresso method, the ratio of water to ground coffee is closer to that of a lungo (110 ml water to $7.5 \mathrm{~g}$ ground coffee). In the case of the lunghi, the content of total solids was slightly more than one percent. The highest value was found for the French Press $(1.43 \% \pm 0.01 \%)$; the lowest, as expected, for the filter coffee extract $(1.03 \% \pm 0.01 \%)$.

The total solids content correlated almost linearly with the refractive index and, hence, with ${ }^{\circ}$ Brix. In fact, it is interesting that the ${ }^{\circ}$ Brix value was found to be linked to a large number of instrumental and sensory attributes. In this study (based on one single type of coffee), a positive correlation of the refractive index ( ${ }^{\circ}$ Brix) with the following attributes was observed: concentration of total solids, headspace intensity, concentration of caffeine, 3-CQA and 5-CQA, and titratable acidity. Furthermore, these attributes were greater with an increase in the following sensory attributes: aroma intensity, body, roasty flavor, bitter flavor, bitterness and astringency in aftersensation.

Acidity and titration NE was the most acidic brew $(\mathrm{pH}$ 5.51), the acidity decreasing ( $\mathrm{pH}$ increasing) from filter coffee to Karlsbader Kanne, Schaerer Espresso, Schaerer Lungo, Dalla Corte Lungo, Dalla Corte Espresso, Bialetti and, finally, French Press (pH 5.92). There was no difference between espresso and lungo extract, so that the different roast degrees for lungo and espresso seem to have had no influence on $\mathrm{pH}$. The lower roast degree of lunghi (which may preserve acids) might have compensated for the higher dilutions. The results are consistent with the literature [3, 5, 15, 34-37].

In respect of titratable acidity, titration needs to be performed with a much higher volume of $\mathrm{NaOH}$ in an espresso than in a lungo to reach the specific value $\mathrm{pH}$ (6.6 or 8), irrespective of the $\mathrm{pH}$ value of the brew itself.

Headspace-SPME-GC/MS The headspace intensity decreased steadily from DE and SE to Bia and the lunghi. There are two possible explanations for this observation. Firstly, the lungo had a higher ratio of water to coffee, leading to lower overall concentrations in the coffee solution and therefore also to lower concentrations of the aroma molecules in the gas phase above the cup. Secondly, the preparation of a lungo took longer, during which the highly volatile aroma molecules were able to evaporate. As the lunghi made with the Dalla Corte and the Schaerer machines had a similar headspace intensity to the other lunghi (French Press, Karlsbader Kanne, filter coffee) while having a much faster extraction time (35-37 s vs. 4-6 min, respectively), the influence of the extraction time seemed to be minor in comparison with the dilution effect.

Content of fatty acids The content of esterified fatty acids in the respective coffee brews was very low (below $0.2 \mathrm{w}-\%)$ in all cases. The French Press extraction showed the highest percentage, resulting from the ground coffee having relatively long contact with hot water, and was perceivable as a film of fat covering the walls of the glass jar. Filter coffee showed the lowest content of fatty acids, as the paper filter appeared to contain them. In Fig. 5, the composition of the esterified fatty acids is shown. Hexadecanoic and octadecadienoic acids amounted to more than $80 \%$ of the fatty acids in total.

Speer and Kölling-Speer [31] reviewed the literature on the lipid fraction of the coffee bean, focusing on the green bean. Roasting seems to have a minor influence on the composition of the fatty acids. Concerning the brew, they reported a higher amount of total lipids for espresso than for filter coffee [31, 38]. Ratnayake et al. [33] also report a much higher concentration of lipids in espresso $(2,260 \mathrm{mg} /$ L) than in metal screen-filtered coffee $(335 \mathrm{mg} / \mathrm{L})$ and drip-filtered coffee $(13 \mathrm{mg} / \mathrm{L})$. Other authors, for example, Jham et al. [39], Martín et al. [40] and Carisano and 
Fig. 4 Content per $10 \mathrm{ml}$ extract prepared according to the different extraction methods (DE, SE, NE, Bia, DL, SL, Bo, $\mathrm{KK}$ and $\mathrm{F}$ ) of (a) total solids in weight percent (TS/w. \%), (b) ${ }^{\circ}$ Brix, (c) $\mathrm{pH}$ value, (d) total headspace intensity in area counts (intensity/counts), amount of $0.1 \mathrm{M} \mathrm{NaOH}$ for titration to (e) $\mathrm{pH} 6.6$ and (f) $\mathrm{pH} 8$ in milliliters $(\mathrm{ml} 0.1 \mathrm{M}$ $\mathrm{NaOH}),(\mathrm{g})$ fatty acids in weight percent (fatty acids/w. \%), (h) caffeine in milligrams (caffeine/mg), (i) 3-O-caffeoyl quinic acid in milligrams (3-CQA/mg) and

(j) 5-O-caffeoyl quinic acid in milligrams (5-CQA/mg). The error bars correspond to the standard deviation of the mean (s95\%)

\section{Content per $10 \mathrm{ml}$ of coffee brew}

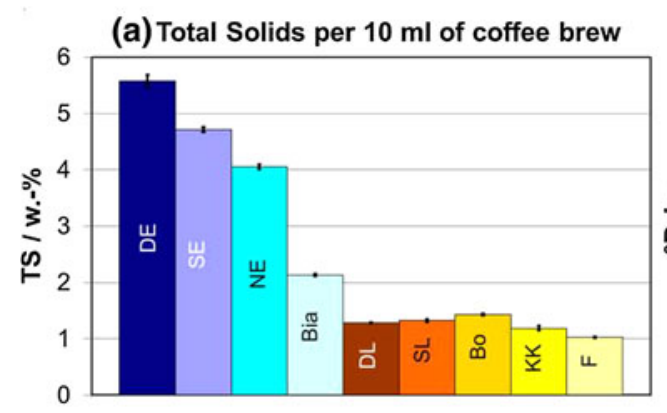

(c) $\mathrm{pH}$ value of coffee extracts

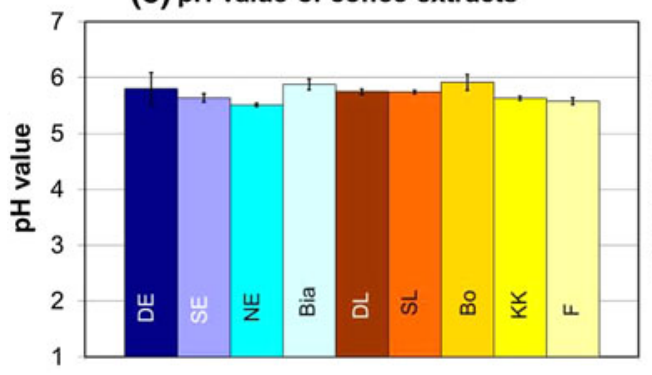

(e) Titratable Acidity to $\mathrm{pH} 6.6$ per $10 \mathrm{ml}$ of coffee brew

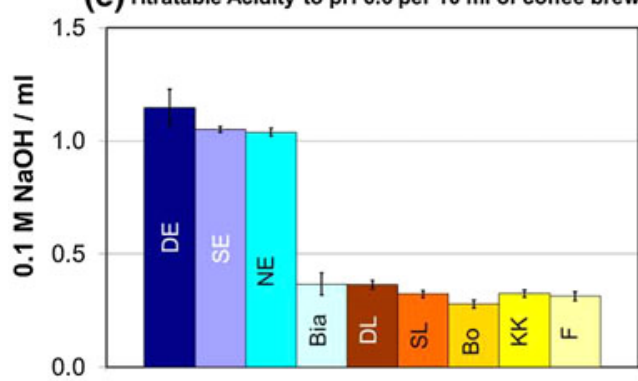

(g) Fatty Acids per $10 \mathrm{ml}$ of coffee brew

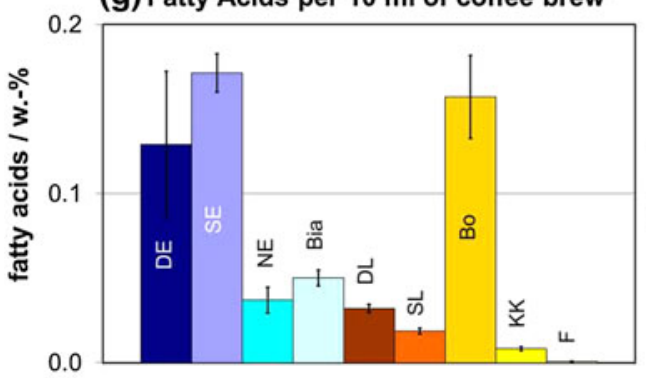

(i) Chlorogenic Acid per $10 \mathrm{ml}$ of coffee brew

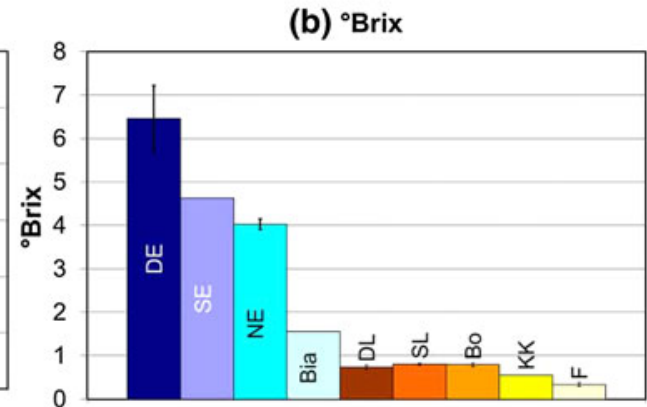

(d) Total HS Intensity

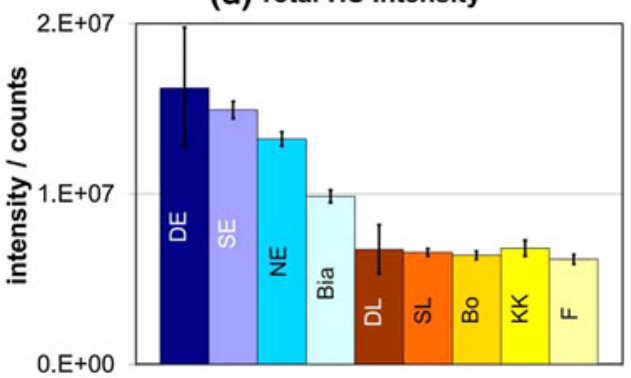

(f) Titratable Acidity to $\mathrm{pH} 8$ per $10 \mathrm{ml}$ of coffee brew

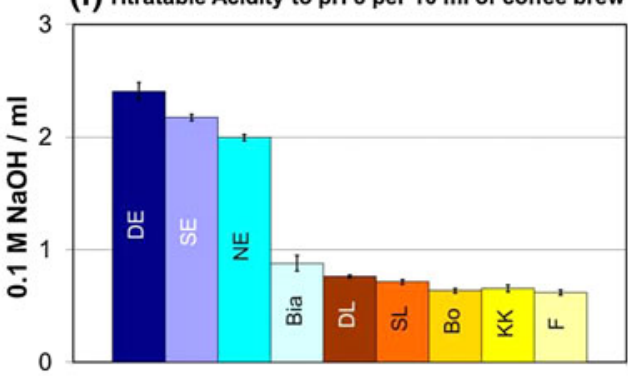

(h) Caffeine per $10 \mathrm{ml}$ of coffee brew

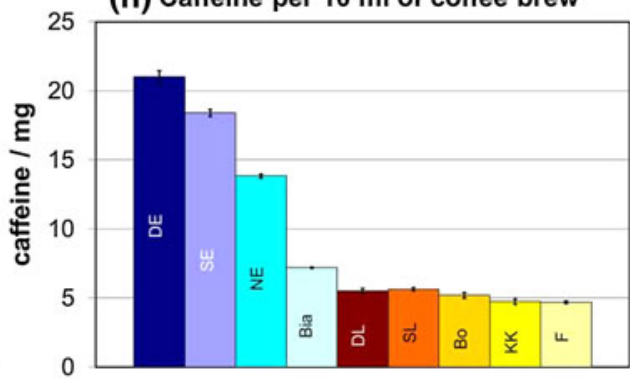

(j) Neochlorogenic Acid per $10 \mathrm{ml}$ of coffee brew

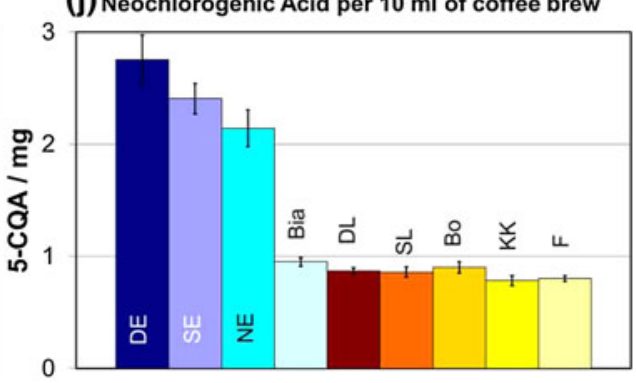

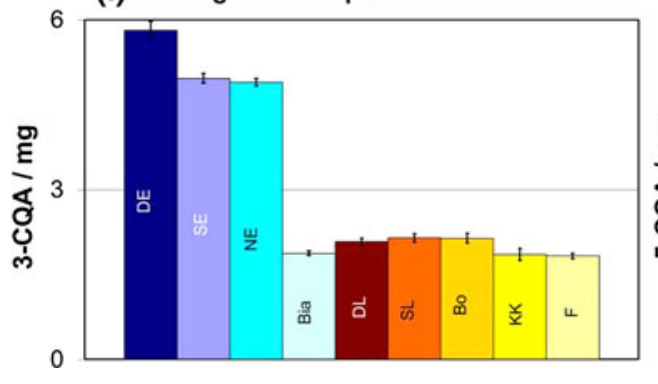

Caffeine The highest concentration of caffeine per sip of Gariboldi [41], found similar results for fatty acids in ground coffee concerning content and composition of fatty acids. coffee was measured in the espressi, with DE containing the highest concentration $((21.0 \pm 0.4) \mathrm{mg} / 10 \mathrm{ml})$ per sip. 


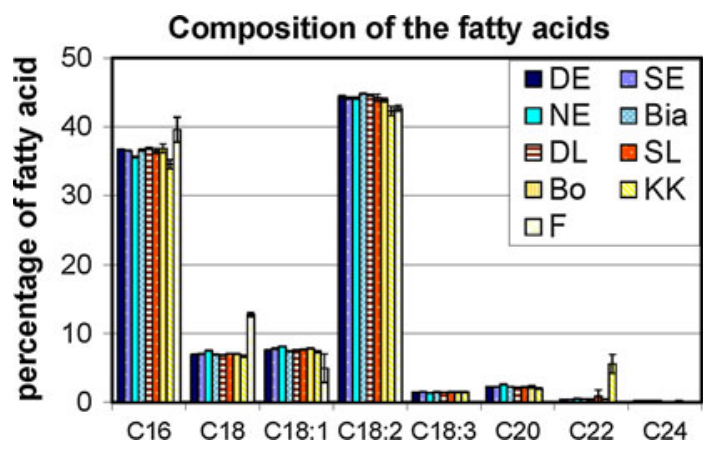

Fig. 5 Composition of the content of the esterified fatty acids of the respective coffee brews in percentage of the total amount of fatty acid methyl esters in the chromatogram. C16: hexadecanoic acid methyl ester, C18: octadecanoic acid methyl ester, C18:1: octadecenoic acid methyl ester, C18:2: octadecadienoic acid methyl ester, C18:3: octadecatrienoic acid methyl ester, C20: eicosanoic acid methyl ester, C22: docosanoic acid methyl ester, C24: tetracosanoic acid methyl ester. The error bars correspond to the standard deviation of the mean in the $95 \% \mathrm{CI}$

Caffeine concentration decreased from SE, NE, Bia to the lunghi DL, SL, and Bo, KK and FF, the latter showing the lowest content per sip of $(4.7 \pm 0.1) \mathrm{mg} / 10 \mathrm{ml}$.

In case of the caffeine concentrations, López-Galilea et al. [3, 4] found slightly lower values for the caffeine content of espresso, mocha, French Press and filter coffee, whereas Peters [5] found slightly higher values for the caffeine concentration for dripfilter coffee, mocha, napolitana and French Press, stating that the caffeine content seems to be a function of the type of coffee used. As Peters did not specify the coffee used for extraction, and as he used different types of coffee for the different extraction methods, the results cannot be compared directly to the results presented here.

Chlorogenic acids In the case of the chlorogenic acids, it was again the espressi that had the highest concentrations, whereas Bia, DL, SL and the filter methods all showed a lower concentration. The values ranged from $(1.83 \pm 0.05)$ $\mathrm{mg} / 10 \mathrm{ml}(\mathrm{F})$ to $(5.8 \pm 0.2) \mathrm{mg} / 10 \mathrm{ml}$ (DE) for 3-CQA and from $(0.78 \pm 0.04) \mathrm{mg} / 10 \mathrm{ml}(\mathrm{KK})$ to $(2.8 \pm 0.2) \mathrm{mg} /$ $10 \mathrm{ml}$ (DE) for 5-CQA, which is consistent with values in the literature [5, 18, 42-44].

In contrast to the lower caffeine concentrations reported by López-Galilea et al. [3], they reported higher 5-CQA values, which may be due either to the Arabica/Robusta blend they used for extraction or to the roast degree of the coffee. Ludwig et al. [37] studied the influence of brewing time on the extraction of antioxidants for espresso and filter coffee and found similar concentrations for caffeine and chlorogenic acids as reported here.

The work of Balakrishnan Nair et al. [45] confirms the results of the presented study, also. They studied the effect of brewing type and the coffee to water ratio on the content of total solids, caffeine and 3-CQA for espresso made with a percolator, espresso extracted with a commercial type of machine and extraction via steeping. In the case of 3-CQA, they report higher concentrations, which may be due to the coffee they used. Unfortunately, they did not specify the coffee they used.

In general, the concentration of the respective components in the brew was highest for espressi, followed by the mocha extraction and the lunghi. The smaller concentration of the compounds in the lunghi with respect to the espressi seemed to be stemming from the differences in the ratios of water to coffee, or in other words, the lunghi were more diluted than the espressi. The extraction time and pressure seemed to have only minor influence, as the lunghi prepared with the fully and semi-automatic coffee machines (short time, high pressure) showed similar concentrations as the lunghi from the infusion methods (long time, low pressure).

The results presented in this study are in accordance with the results presented by López-Galilea et al. [3, 4] and Peters [5]. Concerning the $\mathrm{pH}$ and the content of total solids, López-Galilea et al. and Peters found similar values, except for the mocha extraction, where Peters found a higher content of total solids caused by a higher coffee to water ratio. They both confirmed a higher headspace intensity for the espresso extraction, mocha and napolitana than for filter coffee and French Press, as did Rocha et al. [46] and Zahm et al. [47].

Several research groups have so far studied the influence of the brewing time and the ratio of water to coffee on the extraction of the constituents of coffee [47-54], showing that most of the water extractable components are washed out in the first few seconds of the extraction process under high pressure. Exceptions are less water-soluble compounds, like 5-CQA or isoflavones, in consistency with the findings of this study. This rapid extraction of the components may explain the higher concentration of the coffee constituents in an espresso compared to a lungo.

\section{Content per cup of coffee}

The content of the different quantities per cup of coffee (30 $\mathrm{ml}$ espresso, $120 \mathrm{ml}$ lungo) is shown in Fig. 6 and in the Electronic Supplementary Material (Supp. Table 3). As the ${ }^{\circ}$ Brix, $\mathrm{pH}$ and headspace intensity are intensive values, there is no differentiation between a sip and a cup. They are therefore not included here.

While the contents per sip showed generally higher concentrations in an espresso compared to a lungo, the situation was often different when considered per cup. Per cup of coffee, the lunghi generally contained just as much of the various components analyzed as the espressi, if not more. However, Bia was often found to be an exception. When consumed as an espresso, with a cup size of $30 \mathrm{ml}$, it 
Fig. 6 Content per cup of coffee brew (30 $\mathrm{ml}$ for DE, SE, $\mathrm{NE}, \mathrm{Bia}$, and $120 \mathrm{ml}$ for DL, SL, Bo, KK, F) prepared according to the different extraction methods (DE, SE, NE, Bia, DL, SL, Bo, KK and F) of (a) total solids in grams (TS/ g), (b) fatty acids in grams (fatty acids/g), amount of $0.1 \mathrm{M}$ $\mathrm{NaOH}$ for titration to (c) $\mathrm{pH} 6.6$ and (d) $\mathrm{pH} 8$, respectively, in milliliters per cup $(\mathrm{ml} 0.1 \mathrm{M}$ $\mathrm{NaOH}),(\mathbf{e})$ caffeine in milligrams (caffeine $/ \mathrm{mg}$ ), (f) 3-O-caffeoyl quinic acid in milligrams (3-CQA/mg) and (g) 5-O-caffeoyl quinic acid in milligrams (5-CQA/mg). The error bars correspond to the standard deviation of the mean (s95\%)

\section{Content per cup of coffee}

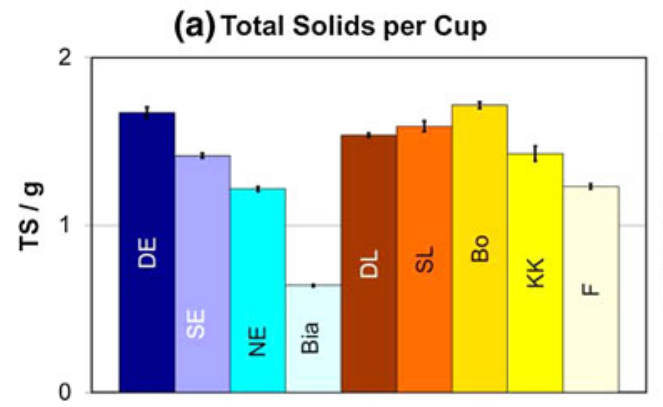

(c) Titratable Acidity to $\mathrm{pH} 6.6$ per cup

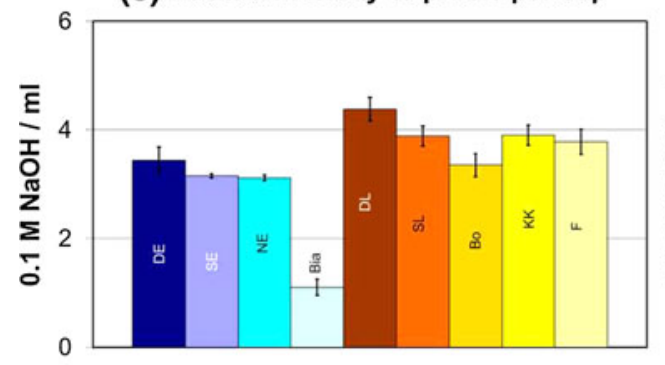

(e)Caffeine per cup

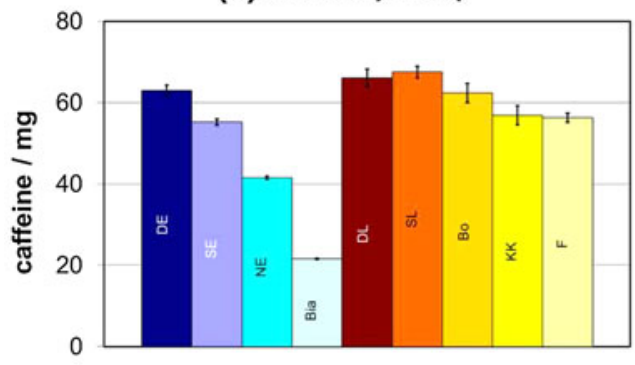

(g) Neochlorogenic Acid per cup

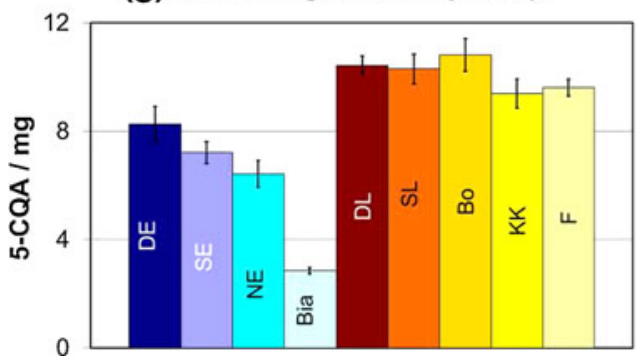

(b) Fatty acids per cup

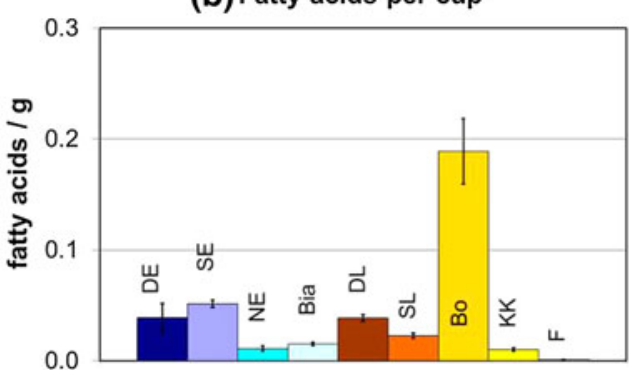

(d) Titratable Acidity to $\mathrm{pH} 8$ per cup

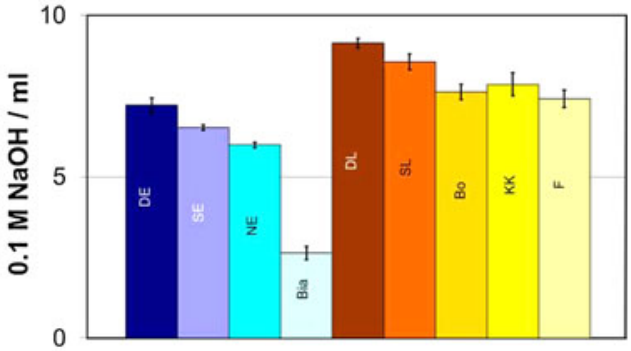

(f) Chlorogenic Acid per cup

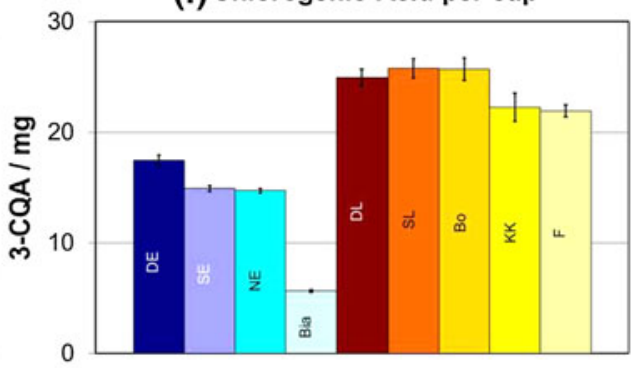

is indeed prepared more like a lungo in terms of the water to coffee ratio (also called the draw-off ratio; see Table 1). Yet, assuming a cup size of $120 \mathrm{ml}$, the amount of the respective component per cup would be four times higher.

Total solids Per cup of coffee, no significant difference was found in total solids between an espresso and a lungo.

Acidity and titration Lunghi were found to have a higher content of titratable acids per cup than espressi. The low value for the Bia extract was striking, which may be explained by the low draw-off ratio.

Content of fatty acids The content of fatty acids per cup of coffee was very low, especially in the case of filter coffee $((0.0010 \pm 0.0002) \mathrm{g} /$ cup $)$. A clear maximum was shown by Bo extraction ((0.19 \pm 0.03$) \mathrm{g} / \mathrm{cup})$. Ratnayake et al. [33] reported similar results for the lipid content of Guatemalan coffee extracts, such as $57 \mathrm{mg}$ per cup of $25 \mathrm{ml}$ espresso, $50 \mathrm{mg}$ per cup $(150 \mathrm{ml})$ for metal screened coffee extract (French Press) and $1.9 \mathrm{mg}$ per cup $(150 \mathrm{ml})$ for drip-filtered coffee.

Caffeine DE, DL, SL and Bo showed a similar content of caffeine per cup of coffee. SE, KK and F contained a little less, NE had a notably smaller amount of caffeine per cup of coffee, and Bia again brought up the rear at $21.6 \mathrm{mg} / \mathrm{cup}$. 
Bell et al. [55] studied the influence of extraction time, volume, grinding and ratio of ground coffee to water on the content of caffeine as well as on the content of total solids for filter coffee and boiled coffee, and reported values comparable to those found in this study. Bunker and McWilliams [56] reported a higher content of caffeine for brews prepared in a dripolator and made with a percolator. However, they did not specify either the coffee they used or their ratio of coffee to water.

The importance of the choice of coffee as well as the way of preparing the coffee brew including the coffee/ water ratio on the amount of caffeine and chlorogenic acids per cup of coffee is highlighted by the recent study of Crozier et al. [43, 57]. Analyzing 20 espressi bought in local coffee shops, the amount of caffeine per serving ranged from $51 \mathrm{mg}$ up to $322 \mathrm{mg}$, corresponding to caffeine concentrations of $1.6-6.5 \mathrm{mg} / \mathrm{ml}$.

Chlorogenic acids The lunghi contained more chlorogenic acids per cup of coffee than the espressi. This was more pronounced in the case of 5-CQA, as it is less water soluble and therefore better extracted when washed out with a higher amount of hot water. In their study on espressi served in local coffee shops, Crozier et al. [43, 57] also measured the content of chlorogenic acids per cup of espresso and found ranges of 5-97 mg per serving for 3-CQA and 12-215 mg per serving for the 5-CQA, consistent with the values found in this study.

In general, the content per cup of coffee $(30 \mathrm{ml}$ for espressi, $120 \mathrm{ml}$ for lunghi) was highest in a lungo, followed by the espressi, and lowest for the mocha extraction. The amount of the analyzed components per cup of coffee brew seemed to be influenced mainly by a combination of extraction temperature and pressure as well as the amount of water used for extraction. The higher the water to coffee ratio, the more was washed out in the cup: the content per cup was higher for the lunghi than for the espressi. The higher the extraction pressure, the more was extracted: the lunghi prepared on the fully and semi-automatic coffee machines had a higher content per cup than the Bayreuth coffee machine extraction and the filter coffee. The temperature, however, was also important: the French Press extraction had similar contents per cup as the lunghi from the fully and semi-automatic coffee machines, although the extraction times were different (4 $\mathrm{min}$ in contrast to $35 \mathrm{~s}$ ). The small amount of components per cup of mocha could be explained by the fact that the mocha extraction is generally regarded as espresso while having a water to coffee ratio like a lungo. If one would have taken a cup of $120 \mathrm{ml}$ of mocha, the content per cup of coffee would have to be multiplied by a factor of four, leading to the highest content per cup of coffee among all extraction types studied here. This was most probably due to the high extraction temperature in the percolator.
The strong influence of the water to coffee ratio on the content per cup of coffee was also shown by Crozier et al. $[43,44]$, analyzing the content of caffeine and chlorogenic acids of 20 different espressi from local coffee shops. Alves et al. [49, 52, 53], studying the influence of the brewing time and procedure (espresso, mocha, filter coffee, press-pot, boiled and Turkish coffee) on the amount of several constituents like tocopherols or isoflavones in coffee brew, highlighted also the big influence of the water to coffee ratio as well as the extraction temperature and pressure on the content of components in the cup of coffee.

\section{Extraction efficiency}

In the preceding sections, the focus was on the coffee itself (a sip or a full cup) as presented to the consumer. We now turn to extraction efficiency, describing the quantity in grams of a given component in the cup per gram of roast and ground coffee $(R \& G)$ that has been extracted. This serves to inform on the technical (and eventually economic) aspects of the extraction mode. The results are given in Fig. 7 and in the Electronic Supplementary Material (Supp. Table 4). In most cases, the lungo extractions were more efficient than the espressi extractions, due to the higher amount of water washing out the ground coffee. This effect was even more pronounced for compounds that are less water soluble, especially the 5-CQA.

The NE extraction efficiency was found to have a relatively higher standard deviation, probably due to variability in the amount of ground coffee per capsule. For all other extracts, the amount of coffee was controlled and hence showed little variability. Among all the different types of extraction investigated, Bia extraction was often the most efficient. This goes in line with studies by PerezMartínez et al. [36] on the influence of the type of extraction on the antioxidant capacity of coffee brew, where they found the highest extraction efficiency of antioxidants in the mocha extraction. This may have been due to the higher extraction temperature in comparison with the other extraction methods. As early as 1958, Merritt and Proctor, among others, reported that a higher extraction temperature led to higher extraction efficiency of soluble solids, caffeine and chlorogenic acids [58].

Total solids The amount of total solids washed out per gram of ground coffee corresponds to the extraction yield. The maximum extraction yield was given by Bia extraction (31.2\%), followed by Bo (26\%). Interestingly, even filter coffee showed a relatively high extraction yield of $19 \%$ in comparison with the other brewing types. Merritt and Proctor [58] reported an extraction yield of 13.8-20.4\% on dry basis at an extraction temperature of $93{ }^{\circ} \mathrm{C}$ and an extraction time of $0.5 \mathrm{~min}$ to $10 \mathrm{~min}$ for gauze filtered coffee. 
Fig. 7 Content per gram of ground coffee $(\mathrm{R} \& \mathrm{G})$ prepared according to the different extraction methods (DE, SE, NE, Bia, DL, SL, Bo, KK and F) of (a) total solids in weight percent (TS/w. \%), (b) fatty acids in weight percent (fatty acids/w. \%), amount of $0.1 \mathrm{M}$ $\mathrm{NaOH}$ in milliliters $(\mathrm{ml} 0.1 \mathrm{M}$ $\mathrm{NaOH})$ for titration to (c) $\mathrm{pH}$ 6.6 and (d) $\mathrm{pH} 8$, respectively, (e) caffeine in weight percent (caffeine/w. \%), (f) total headspace intensity in area counts per gram (intensity/ counts), (g) 3-O-caffeoyl quinic acid in weight percent (3-CQA/ w. \%) and (h) 5-O-caffeoyl quinic acid in weight percent (5-CQA/w. \%). The error bars correspond to the standard deviation of the mean (s95\%)

\section{Content per gram of R\&G}

(a) Total Solids per g R\&G

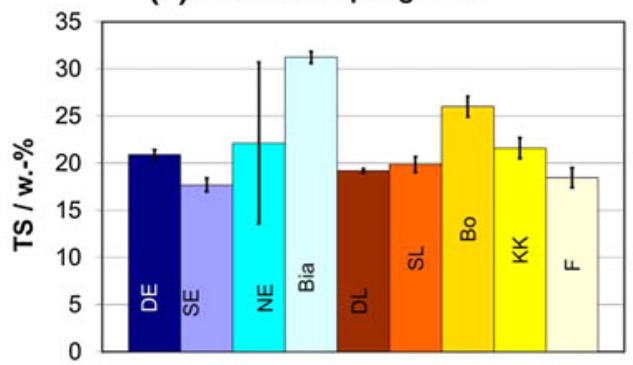

(c) Titratable Acidity to $\mathrm{pH} 6.6$ per $\mathrm{g}$ R\&G

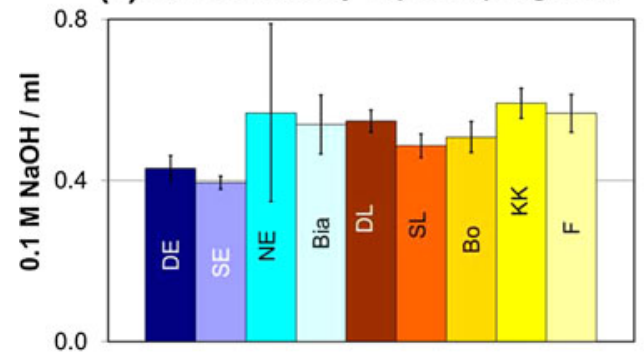

(e) Caffeine per g R\&G

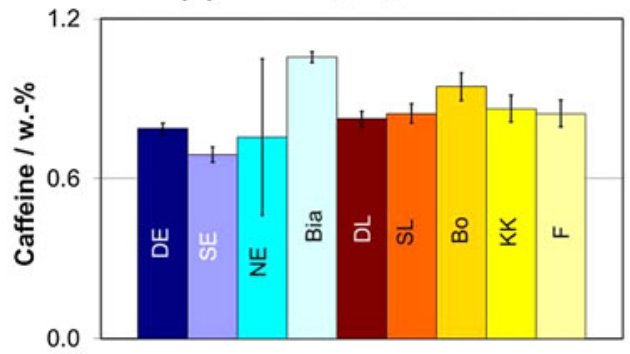

(g) Chlorogenic Acid per g R\&G

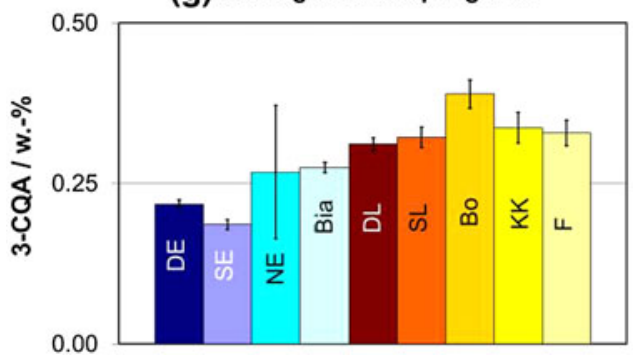

(b) Fatty Acids per g R\&G

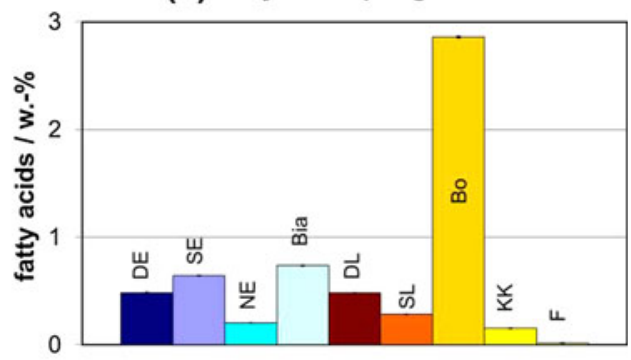

(d) Titratable Acidity to $\mathrm{pH} 8$ per g R\&G

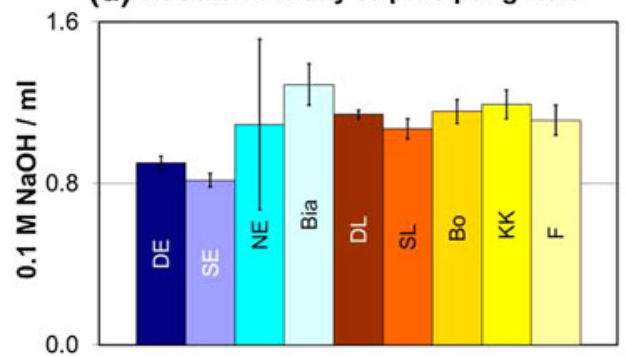

(f) Total HS Intensity per g R\&G

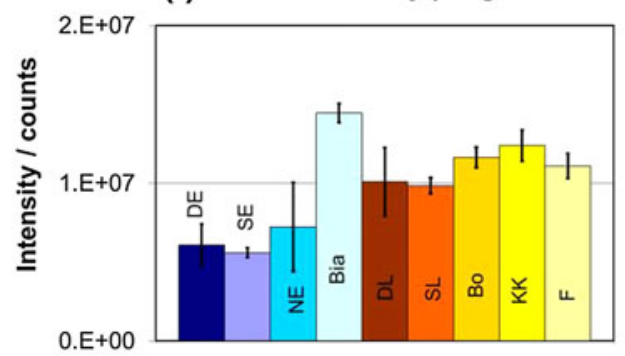

(h) Neochlorogenic Acid per g R\&G

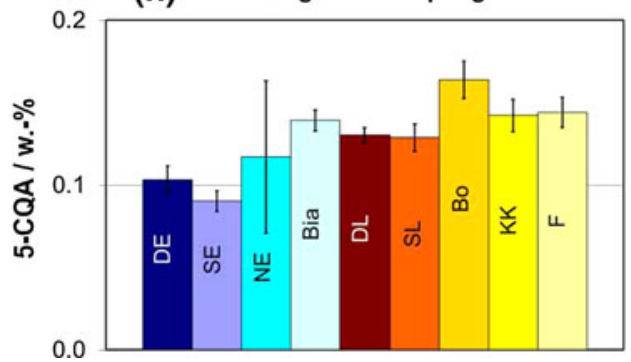

Titratable acidity DE and SE extract had significantly fewer extracted acids per gram of ground coffee than all the other brewing types, the latter showing no significant differences (except Bia). Titration to $\mathrm{pH} 8$ revealed one exception, that is the Bia brewing method, which had a relatively higher extraction efficiency for acids in the range from $\mathrm{pH} 6.6$ to 8.0.

The higher extraction efficiency for acids found in a lungo relative to an espresso may be explained by the following: (i) the larger amount of water in a lungo resulted in a higher degree of extraction or (ii) the darker roast used for espresso led to a stronger degradation and loss of acids in the roasted coffee beans. Considering that the Bia extract, which was prepared from a dark roasted coffee and a ratio of water to coffee similar to a lungo, showed a high amount of extracted acids, the first explanation may be more plausible here.

Headspace intensity Bia showed a clear maximum headspace intensity. The filter methods, surprisingly, also yielded high extraction efficiency for volatile compounds per gram of R\&G. These brewing methods were therefore able to produce an intense coffee aroma from a relatively small amount of ground coffee. As expected, the intensity of the aroma above the coffee (per gram of $R \& G$ ) was much higher for an espresso than for a lungo, as shown in Fig. 4. 
Content of fatty acids The most efficient extraction of fatty acids was performed with French Press extraction. Brewing with a paper filter resulted in coffee with the lowest fatty acid content, which is consistent with the findings of Peters [5].

Caffeine and chlorogenic acids The extraction efficiency of caffeine was comparable to that of total solids, with the exception of filter coffee. The latter showed a relatively higher efficiency for caffeine than for total solids (extraction yield), most probably because the solids are retained in the paper filter, whereas caffeine is not. The extraction efficiency of 3-CQA was similar to that of caffeine in the case of the lunghi. Bia showed a much lower extraction efficiency of 3-CQA in comparison with caffeine. The espresso brewing methods were found to extract the 3-CQA much less efficiently than the lunghi brewing methods. In the case of 5-CQA, this was even more pronounced. Our values for the extraction efficiency of caffeine, 3-CQA and 5-CQA are consistent with values in the literature [35, 58]. Ludwig et al. [37] compared filter coffee with espresso extraction and Perez-Martínez et al. [36] compared espresso extraction with mocha, filter and plunger coffee extraction regarding the extraction efficiency of antioxidants. Both confirm a higher extraction efficiency of antioxidants for filter coffee and mocha extraction, respectively, than for espresso.

The differences in the extraction efficiencies of caffeine, 3-CQA and 5-CQA can be explained either by the water solubility of the respective quantities, decreasing from caffeine $\left(20 \mathrm{~g} / \mathrm{L}\right.$ at $20{ }^{\circ} \mathrm{C} \mathrm{[59])} \mathrm{to} \mathrm{3-CQA} \mathrm{(soluble} \mathrm{in} \mathrm{hot}$ water [60]) to 5-CQA (personal experience of the authors) or by a decreased amount of chlorogenic acids in the espresso powder itself, due to the darker roast degree. Bia extraction showed a higher degree of extraction than the lunghi for all compounds analyzed, except for the chlorogenic acids. The darker roast degree for the espressi could account for this difference. French Press extraction showed the most efficient extraction of 3-CQA and 5-CQA, due to the long extraction time with relatively hot water. This is consistent with the findings of Merritt and Proctor, who found a higher extraction efficiency for caffeine and chlorogenic acids with prolonged extraction time and higher extraction temperature [58]. The results presented here are also consistent with Zanoni et al. [61], who found a higher content of total solids and caffeine with prolonged extraction time.

Regarding the extraction efficiency, the mocha extraction was the most efficient brewing method, followed by the lunghi and the espressi. The most influencing parameters seemed to be the extraction temperature and time. Within the infusion methods, the French Press extraction had the highest extraction efficiency (high extraction time and temperature), followed by the Bayreuth coffee machine extraction and the filter coffee (high extraction time, low pressure), whereas the lunghi of the fully and semi-automatic coffee machines (short extraction time, high pressure) showed the smallest extraction efficiency. López-Galilea et al. [3], Ludwig et al. [37] and Perez-Martínez et al. [36] reported higher extraction efficiencies, also, with prolonging the contact time of the water with the coffee powder, especially in the case of less water-soluble substances, consistent with the findings of this study. The comparatively low extraction efficiency for chlorogenic acids of the mocha and the espressi extractions may be explained partly by their low water solubility, but partly also by the darker roast degree used for these extraction methods.

In general, concerning the extraction efficiencies, the higher amount of water used for the preparation of a lungo led to higher extraction efficiencies for the lunghi than for the espressi. The values presented here differ somewhat to the values of Peters [5]. This may be due to the difference in coffee they used, to the roast or milling degree of the coffee as well as to the different water to coffee ratio. To clarify the influence of these factors, detailed experimental studies would be needed. Ludwig et al. [37] compared the temporal evolution of the extraction process between an espresso and filter coffee and showed that more than $70 \%$ of the antioxidants are washed out in the first eight seconds of an espresso extraction. For filter coffee, they reported an U-shaped time-concentration profile of the extracted antioxidants. The peak in extraction efficiency at the end of the extraction process is explained by a longer contact time of the water with the coffee powder caused by the water pressure release at the end of the extraction process (there is no more water lying above the coffee powder pulling down due to gravity). Combining the results of this study and of Ludwig et al. means that in an espresso, the components were extracted quickly, but not very efficiently. The preparation of a lungo under high pressure (fully and semi-automatic coffee machine) extracted the components quickly, also, but the higher amount of water led to a higher extraction efficiency. In filter coffee, the extraction was slower and most efficient in the beginning and at the end of the extraction process, according to Ludwig et al. [37]. This extraction peak at the end of the brewing seemed to compensate for the lack of pressure during the extraction, because the study presented here shows similar extraction efficiencies for lunghi prepared with (DL, SL) or without (KK, F) high pressure.

The degree of grinding seemed to have a minor influence, here, in comparison with the water to coffee ratio: the lunghi DL and SL, prepared with a coarser grind, had a higher extraction efficiency than the corresponding espressi $\mathrm{DE}$ and SE, prepared with a finer ground and smaller water to coffee ratio. In general, of course, the extraction efficiency increases with decreasing particle size, as was 
shown, for example, by Andueza et al. [62] and Spiro et al. [63].

Sensory evaluation

The results of the consensus profiling of the different coffee brewing methods are shown in Figs. 8, 9 and 10 and reveal clear differences between the respective extraction methods.

Concerning the crema, only DE, SE, DL, SL and NE were evaluated, as the other types of extraction do not generate a crema. NE had noticeably the highest amount of crema with the most intensive color, whereas DE had the finest crema.

The texture/body of the respective brews was clearly highest in the case of the espressi DE, SE and NE, and the lowest for $\mathrm{KK}$ and $\mathrm{F}$.

Aroma DE and SE not only had the highest overall aroma intensity, but also the highest intensity of the roasty aroma. The filter extractions $\mathrm{KK}$ and $\mathrm{F}$ were found to have the least aroma intensity. KK extraction and SE extraction exhibited a surprisingly high intensity of fruity aroma.

In the flavor profile, the KK extraction had a negligible fruity note, but a high intensity of sweetness. Filter coffee showed a relatively weak but very well-balanced flavor profile. The flavor profile of Bo, SL and DL was also well balanced. The differences in acidity between the extraction methods were minor. In the case of the espressi, the roasty and bitter attributes clearly dominated the flavor of the coffee brew.

Aftersensation The bitterness of the espressi remained in the aftersensation and was perceivable in the lunghi DL and SL as well as in Bo. KK and F showed a small but well-balanced profile in the aftersensation. Acidity was only a minor attribute in the aftersensation. The aftersensation aroma decreased from DE, SE and NE to Bia, DL and SL, to Bo and F, and finally to KK. Astringency diminished in a similar way.

Advantages and shortcomings of the respective extractions

\section{Espressi}

Sensory Aspects All the espressi extractions were characterized by a strong roasty and bitter flavor, a pronounced body and a prolonged aftersensation. The crema was the parameter which differed most between the respective
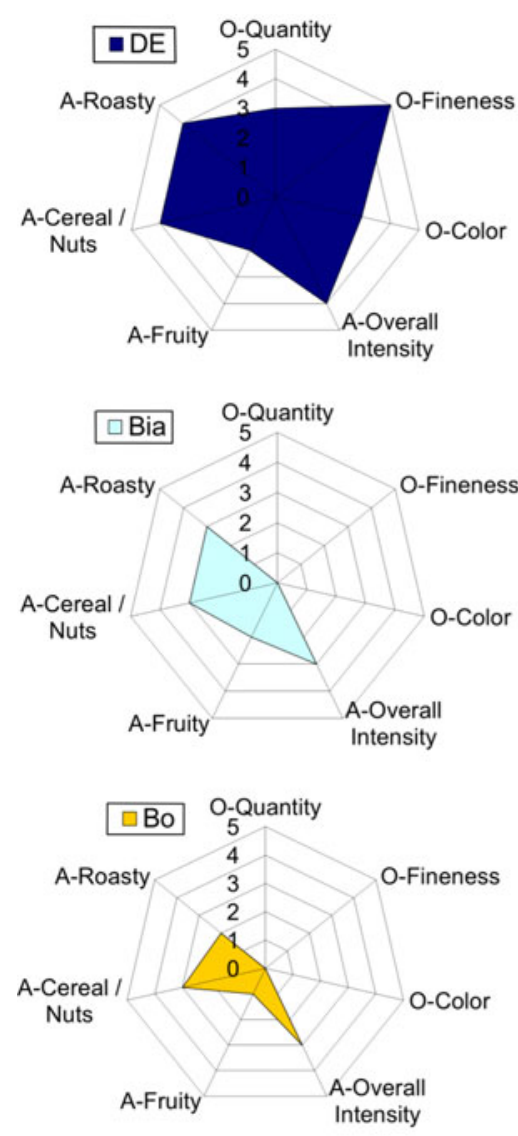
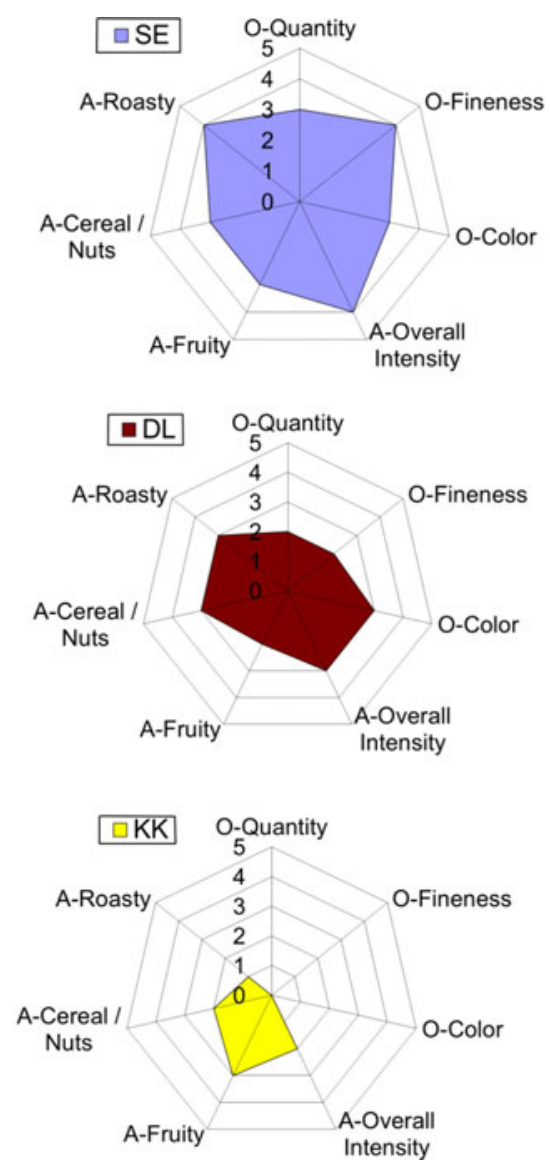
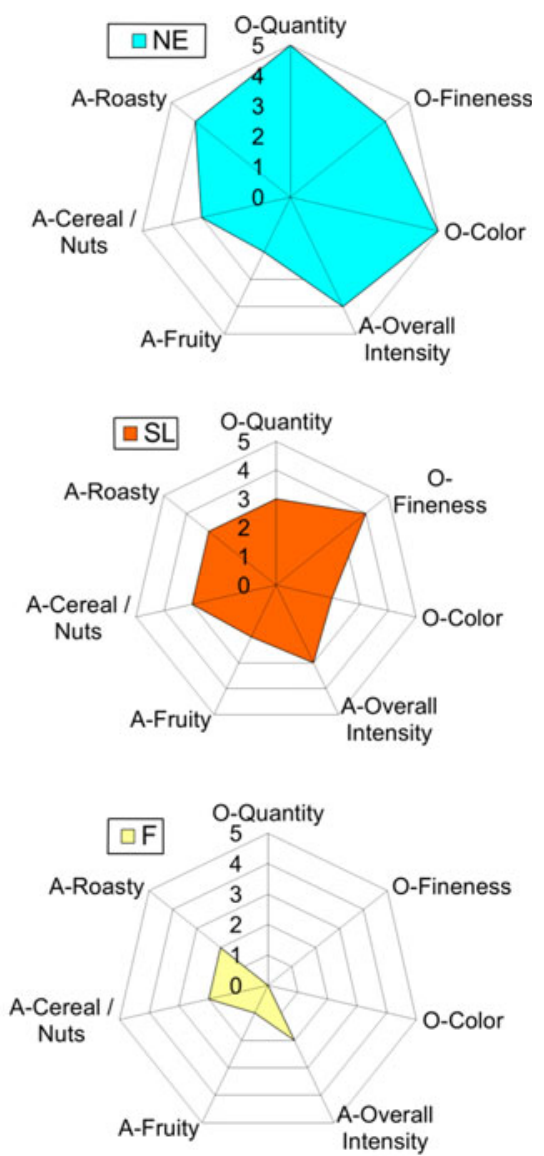

Fig. 8 Sensory profiles of the respective extraction types (DE, SE, NE, Bia, DL, SL, Bo, KK, F) for Optic of crema (O-Quantity, O-Fineness, O-Color) and Aroma (A-Overall Intensity, A-Fruity, A-Cereal/Nuts, A-Roasty) 

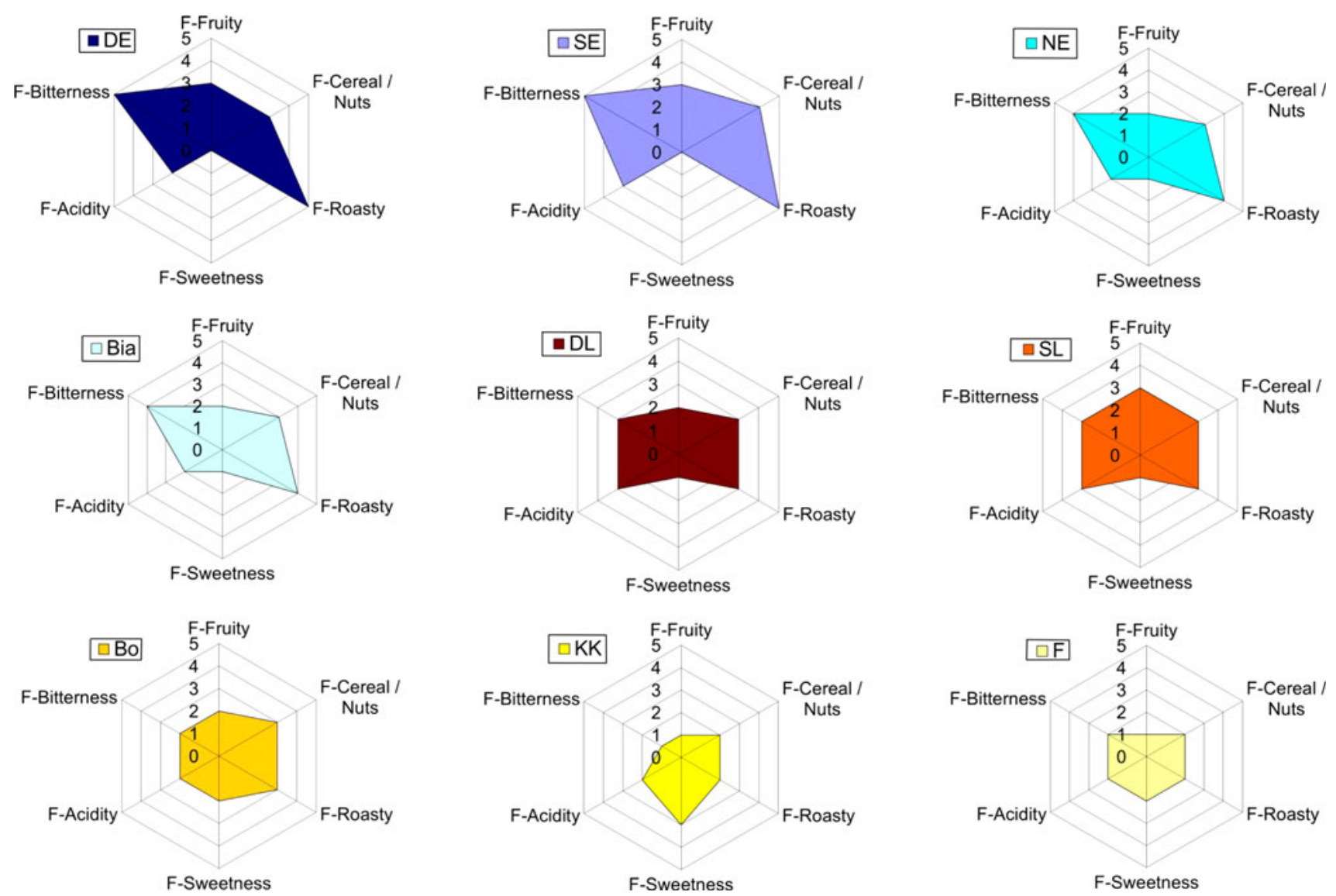

Fig. 9 Sensory profiles of the respective extraction types (DE, SE, NE, Bia, DL, SL, Bo, KK, F) for Flavor (F-Fruity, F-Cereal/Nuts, F-Roasty, F-Sweetness, F-Acidity, F-Bitterness)

espresso extraction methods. Espresso from a semi-automatic coffee machine showed a fine crema, darker than the crema of an espresso made with the fully automatic coffee machine. The single-serve capsule system was the extraction with the highest quantity of the darkest crema.

Analytical Aspects The espressi showed the highest concentration of TS, the highest concentration of titratable acids and the highest concentrations of caffeine, 3-CQA and 5-CQA. The $\mathrm{pH}$ values of the different espressi were similar.

\section{Lunghi}

Sensory Aspects In general, DL and SL showed a little less intensity than the corresponding espressi, but still a higher intensity than the other lungo extractions. The main difference between SL and DL was the crema, which was finer, lighter and found in a higher quantity in the case of SL. Hence, DE performed better than SE with respect to crema, while the situation was reversed for the lunghi.

The infusion methods Bo, KK and $\mathrm{F}$ were characterized by modest aromaticity, a relatively weak roasty and bitter note, and a pronounced sweetness.
Analytical Aspects There were only minor differences between the respective lunghi extractions regarding the concentrations of total solids, titratable acids, caffeine, 3-CQA and 5-CQA, as well as in respect of the ${ }^{\circ}$ Brix value and the headspace intensity. In most cases, filter coffee brought up the rear with the lowest intensity of the respective attributes.

\section{Main characteristics of the extractions}

$D E$ highest fineness of crema, strong roasty note, highest cereal/nuts score for aroma, highest bitterness in flavor (together with SE), highest ${ }^{\circ}$ Brix value.

$S E$ strong fruity note in aroma, distinct roasty note, highest cereal/nuts score for flavor, highest acidity and bitterness in aftersensation, highest bitterness in flavor (together with DE).

$N E$ darkest crema, highest amount of crema, strong roasty note, highest body, lower $\mathrm{pH}$ value, negligible fatty acid content (note: different type of coffee; not Antigua Guatemala).

Bia no crema, middle-range sensory values, same flavor profile as NE although they are based on a different 

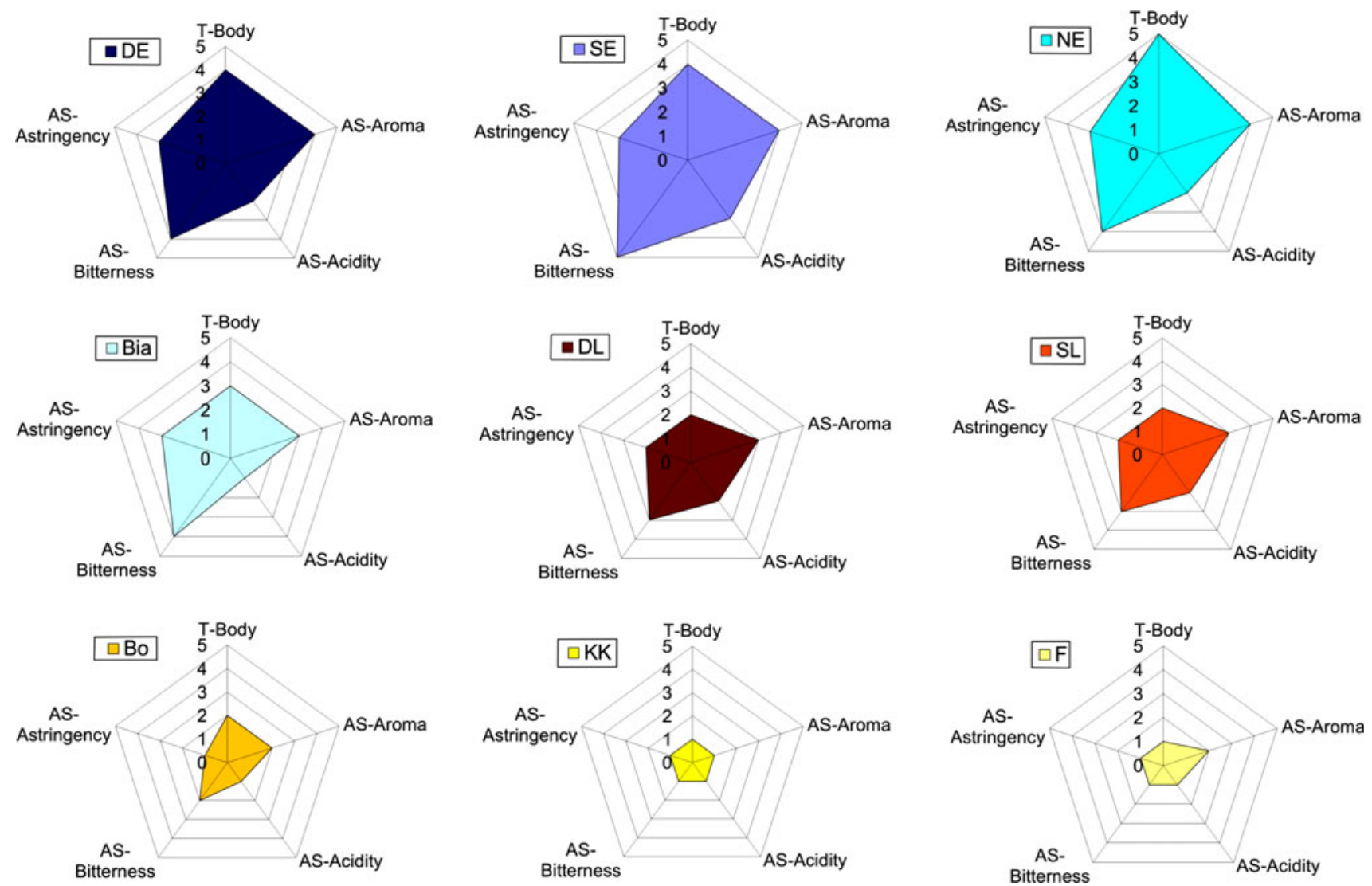

Fig. 10 Sensory profiles of the respective extraction types (DE, SE, NE, Bia, DL, SL, Bo, KK, F) for Texture (T-Body) and Aftersensation (ASAroma, AS-Acidity, AS-Bitterness, AS-Astringency)

coffee; positioned between espresso and lungo from an analytical point of view; relatively high amount of fatty acids.

$D L, S L$ Both are characterized by a total solids content of circa $1.3 \%$ and a $\mathrm{pH}$ of 5.7, which is in the mid-region of all extraction types studied here. The DL shows a slightly higher titratable acidity and a higher content of fatty acids than the SL. In sensory, they are characterized by a balanced mid-score aroma and taste impression. In the aftersensation, aroma and bitterness are pronounced. The biggest differences between DL and SL were the optic and quantity of crema.

Bo higher roasty note, higher aromaticity, stronger cereal/nuts note, more body and more bitterness than the other filter methods (KK and F); highest amount of fatty acids, high $\mathrm{pH}$ value.

$K K$ high intensity of fruity aroma, pronounced sweetness in flavor, moderate aromaticity, relatively low roasty note and bitterness; relatively low $\mathrm{pH}$ value.

$F$ well-balanced profile, with low fruity note; negligible content of fatty acids, low $\mathrm{pH}$ value.
Comparison of analytics with sensory

In analytics, absolute quantities or concentrations are measured, in this study for a sip and a whole cup of coffee, and per gram of R\&G (extraction efficiency). In sensory evaluation, the panelists tasted a sip of coffee. Hence, the most appropriate analytical data to be correlated with the sensory profiles were those for a sip of coffee, that is, for $10 \mathrm{ml}$ of coffee brew (corresponding to circa one sip of coffee for an adult), as summarized in Fig. 4. The sensory results are given in Figs. 8, 9 and 10. The following correlations were observed with the respective correlation coefficients (significance was approved by a one-sided $\mathrm{F}$ test at the alpha $=0.1$ level): $r^{2}$ (total solids vs. texture/ body) $=0.69, r^{2}$ (headspace intensity vs. aroma overall intensity $)=0.73, r^{2}$ (caffeine vs. AS-bitterness $)=0.69$, $r^{2}$ (caffeine vs. AS-astringency) $=0.75, r^{2}$ (sum of 3-CQA and 5-CQA vs. AS-bitterness) $=0.68, r^{2}$ (sum of 3-CQA and 5-CQA vs. AS-astringency) $=0.75$; for the following two correlations, we have observed smaller correlation coefficients classified only as a trend of positive 
correlation: $r^{2}$ (caffeine vs. F-bitterness) $=0.58, r^{2}$ (sum of 3-CQA and 5-CQA vs. F-bitterness) $=0.51$.

\section{Content of total solids versus texture/body}

The higher the content of TS, the higher the body was rated by the panelists. The high scores for body of NE in comparison with its content of TS were striking. This may have been due to the influence of the huge amount of crema.

\section{Headspace intensity versus aroma intensity}

The higher the sensory overall intensity in aroma, the higher is the total headspace intensity in the HS SPME GC/MS measurements.

\section{pH value, titratable acidity versus acidity in flavor and aftersensation}

In this study, no correlation between $\mathrm{pH}$ or titratable acidity and perceived acidity in flavor or aftersensation was found. Bia extraction is worthy of note, as it achieved the highest score for flavor acidity while being the least acidic coffee brew (highest $\mathrm{pH}$ value).

Furthermore, the $\mathrm{pH}$ value of the brew and the titratable acidity did not correlate with one another. It should be borne in mind that many acids which exist in a coffee brew are not (fully) deprotonated at the $\mathrm{pH}$ of the brew, and thus do not contribute to the brew's $\mathrm{pH}$ value, but are measured during titration with a base.

The lack of correlation between these attributes may be explained by the small differences in acidity of the different extraction types in the sensory evaluation. Interactions with other sensory attributes may be superimposed at this point. For example, perceived bitterness is affected by changes in the $\mathrm{pH}$ of a beverage (see, e.g., Reference $[64,65])$. However, the question of whether high bitterness masks the acidity of a brew cannot be answered at this point. In addition, the temperature of the servings may have an influence on the perception of acidity. In general, acidity is more pronounced at lower temperatures of the coffee brew. As the Bo extraction has the same intensity in flavor acidity as the $\mathrm{KK}$ and filter coffee extracts while having a higher temperature, the influence of the temperature of the extract seems to be minor.

The correlation of the $\mathrm{pH}$ value and/or the titratable acidity with the sensory perceived acidity has been widely studied. Andueza et al. [54] did not find a correlation of the $\mathrm{pH}$ value with sensory perceived acidity, either. In contrast to this study, Fuse et al. [66] found a correlation between the $\mathrm{pH}$ value of the brew, the roast degree, the titratable acidity and the sourness intensity of the brew studying the acidity of Guatemala filter coffee by flow injection analysis with electrochemical detection. The range of titratable acidity, however, was much larger than in this study (15-30 ml $0.1 \mathrm{M} \mathrm{NaOH}$ to $\mathrm{pH} 8.2$ per $50 \mathrm{ml}$ of coffee brew, Fuse et al., versus 3-12 $\mathrm{ml} 0.1 \mathrm{M} \mathrm{NaOH}$ to $\mathrm{pH} 8$ per $50 \mathrm{ml}$ of coffee brew, this study).

Clifford [67] stated in 1988 that "in effect, the reaction of the acid with the receptor is a titration, and thus very similar to the process used in measuring titratable acidity." He cited studies of Voilley et al. (1981) and Harvey (1920) who found no correlation between the $\mathrm{pH}$ value and the perceived acidity, but mentioned that the perceived acidity also depends on the reserve acidity due to undissociated acids.

Maier et al. [12, 64, 68-73] performed an extensive study on the acids in coffee, ranging from the composition of the acids in coffee to the correlation of the analytically measured acidity with the sensory attribute acidity. The sensory evaluation was performed on cold coffee extracts $\left(40{ }^{\circ} \mathrm{C}\right)$ diluted with water and showed a linear correlation between the titratable acidity to $\mathrm{pH} 6$ and the acidic taste of different coffee extractions, but no correlation with the $\mathrm{pH}$ value of the brews. In their studies, they identified $67 \%$ of the acids contributing to the titratable acidity as well as the sensory acidity of the coffee extract, with acetic and citric acid being the most important ones.

Rodrigues et al. [42] analyzed the organic acids with UV/HPLC of several Arabica and Robusta coffees as well as the sensory acidity. Concerning the Robusta coffees, they found a good correlation between the total amount of organic acids and the sensory acidity, but no correlation in the case of the Arabica brews. Lugaz et al. [74] performed an extensive study on the perception of acid taste in general as a function of saliva flow rates, $\mathrm{pH}$ and chemical composition of the acid and concluded that the titratable acidity rather than the $\mathrm{pH}$ should contribute to the acid taste.

According to Sivetz et al. [75], who studied the influence of acidity on coffee flavor in 1972, none of our coffee brews falls into the acceptable range of palatability, lying between $\mathrm{pH} 4.95$ and $\mathrm{pH} 5.15$ for an Arabica coffee. Interestingly, none of the panelists were complaining about the palatability of the respective coffee brews. This may be due to a shift in consumer's preferences in the last 40 years to coffees with a less pronounced acid taste.

\section{Caffeine, chlorogenic acids versus bitterness, astringency}

There was a tendency toward higher sensory scores for bitterness and astringency in flavor and aftersensation with increasing amounts of caffeine. This was even more pronounced with increasing amounts of chlorogenic acids.

One exception is again Bia extraction: The bitterness in the sensory results scored much higher than would have been assumed with respect to the concentration of caffeine 
and chlorogenic acids. The relatively high bitterness of Bia is most probably due to other compounds in the coffee brew.

The studies of Andueza et al. [54] on the influence of the ratio of ground coffee to water in espresso extraction also showed no significant correlation between increasing content of caffeine and chlorogenic acids with increasing bitterness and astringency. Frank et al. [76, 77] and Kreppenhofer et al. [78] have recently identified a range of substances responsible, among others, for bitterness in coffee brews. Taste dilution analysis showed that compounds like caffeoyl-quinides, di-caffeoyl-quinides, feruloyl-quinides ("pleasant bitterness of coffee"), 4-vinylcatechol oligomers ("harsh and espresso-like bitterness"), as well as (furan-2-yl) methylated benzene diols and triols ("astringent mouth feel and clear bitter taste") contributed significantly to the bitterness of a coffee brew. Caffeoyl-quinides, di-caffeoyl-quinides, feruloyl-quinides and (furan-2-yl) methylated benzene diols and triols also contributed to the astringency of the coffee brew [76, 78]. The chlorogenic acids 3-CQA and 5-CQA, however, produced no bitter taste. The correlation found in our study between the chlorogenic acids and the perceived bitterness in taste can therefore not be ascribed to the concentration of 3-CQA and 5-CQA. Most probably, the concentration of substances responsible for the bitter taste has a similar dependence on the extraction method as 3-CQA and 5-CQA. Blumberg et al. [48] showed that the more polar the bitter-tasting compound, the faster it is extracted with hot water, monocaffeoyl quinides ("pleasant bitterness of coffee"), for example, being already extracted to about one-third of their total content in the first $10 \mathrm{ml}$ of coffee.

\section{Sweetness and optic of crema}

The sensory attributes sweetness and optic of crema do not have any analytical pendant in this study. In principle, the crema may influence sensory evaluation by altering the distribution of coffee in the mouth, leading to either an increase in intensity of the sensory attributes like roasty or a masking of attributes like bitterness [1, 79]. In addition, the crema may act as "an aroma-sealing lid" [1], retaining the lower volatile organic compounds in the coffee whereas enhancing the high volatile organic compounds in the headspace [53]. In fact, we observed a three-step ranking in intensity of the sensory attributes in the sensory evaluation: (i) high scores for the espressi (with crema), (ii) middlerange scores for the lunghi with crema and (iii) lower scores for the lunghi without crema. However, in the analytical measurements of the concentrations of the respective quantities, we observed, roughly speaking, a high intensity for the espressi and a low intensity for the lunghi. This was also reflected in a principal component analysis (PCA) of the sensory and analytical data (Fig. 11). In the sensory data, the same three groups can clearly be identified, from odor intense coffees with strong bitterness and body (with crema) to less intense coffees (lunghi from automatic and semi-automatic coffee machines, with crema, and Bia) to sweet- and low-bodied coffees (lunghi without crema). This three-level ranking in the sensory data is not reflected in the instrumental results, which have been classified into two categories, espressi and lunghi, as shown in Fig. 11b. In other words, the clear differentiation between lunghi with or without crema in the sensory evaluation was not reflected in the instrumental data. As the sensory evaluation was performed by a trained panel, visual influence by the crema is unlikely, suggesting that the sensory interaction, that is, the density of the crema in the mouth, is more important.

\section{Conclusions}

Nine of the most common extraction methods of preparing a cup of coffee were characterized: espresso and lungo with a semi-automatic coffee machine, espresso and lungo with a fully automatic coffee machine, espresso from a singleserve capsule system, mocha made with a percolator and
Fig. 11 Biplot from the principal component analysis of (a) the sensory data (PC1 vs. $\mathrm{PC} 2,78 \%$ of total variance) and (b) the chemical data (PC1 vs. PC2, $96 \%$ of total variance) (a) Sensory Data

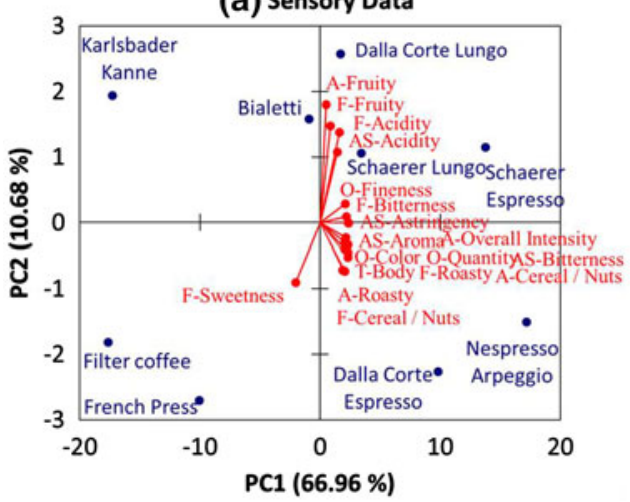

(b) Chemical Data

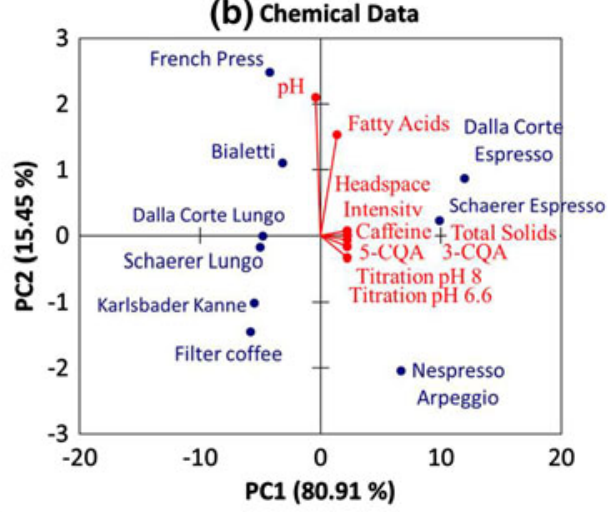


lunghi prepared with a French Press, a Bayreuth coffee maker and filter coffee.

The technical differences in these extraction methods led to differences in the quantity of the analytical aspects studied, exhibited different extraction efficiencies and, last but not least, extracted coffees with different sensory profiles. In general, the espressi showed a higher concentration of the respective quantities than the lunghi. However, when the contents per cup were compared, the lunghi generally had a higher content than the espressi. Hence, the overall uptake of coffee components is higher when drinking a lungo, although the consumer does not necessarily notice this as the concentration, and therefore the sensory experience, is lower in a lungo.

The extraction efficiency of the respective compounds was mainly driven by their solubility in water, a higher amount of water, as in the extraction of a lungo, generally leading to higher extraction efficiency. A prolonged extraction time and/or a higher extraction temperature further enhanced extraction efficiency.

Comparing the analytical aspects with the sensory evaluation, the following positive correlations were revealed

- total solids-texture/body

- headspace intensity—aroma intensity

- concentrations of caffeine/chlorogenic acids-bitterness and astringency.

There was neither a correlation of the $\mathrm{pH}$ value nor of the titratable acidity with the sensory aspect of acidity.

In conclusion, this study describes the analytical and sensory properties of nine different types of coffee extraction, based on Guatemalan coffee. It was not the aim of the study to establish the best means of coffee extraction, as this is driven mainly by the personal preferences of the consumers, who will set their own standards for a good cup of coffee.

Conflict of interest The authors declare that they have no conflict of interest.

Open Access This article is distributed under the terms of the Creative Commons Attribution License which permits any use, distribution, and reproduction in any medium, provided the original author(s) and the source are credited.

\section{References}

1. Petracco M (2001) Technology IV: beverage preparation: brewing trends for the new millennium. In: Coffee: Recent Developments. Blackwell Science, London

2. Illy A, Viani R (2005) Espresso coffee: the science of quality. Elsevier, Amsterdam
3. López-Galilea I, Paz de Peña M, Cid C (2007) Correlation of selected constituents with the total antioxidant capacity of coffee beverages: influence of the brewing procedure. J Agric Food Chem 55:6110-6117

4. López-Galilea I, Fournier N, Cid C, Guichard E (2006) Changes in headspace volatile concentrations of coffee brews caused by the roasting process and the brewing procedure. J Agric Food Chem 54:8560-8566

5. Peters A (1991) Brewing makes the difference. ASIC-14eme Colloque Scientifique International sur le Café, ASIC, Paris, pp 97-106

6. Yeretzian C, Pollien P, Lindinger C, Ali S (2004) Individualization of flavor preferences: toward a consumer-centric and individualized aroma science. Comp Rev Food Sci Food Saf 3:152-159

7. Roberts DD, Pollien P, Antille N, Lindinger C, Yeretzian C (2003) Comparison of nosespace, headspace, and sensory intensity ratings for the evaluation of flavor absorption by fat. J Agric Food Chem 51:3636-3642

8. Roberts DD, Pollien P, Lindinger C, Yeretzian C (2003) Nosespace analysis with proton-transfer reaction mass spectrometry: Intra- and Interpersonal Variability. In: Handbook of flavor characterization: sensory analysis, chemistry, and physiology. Dekker, New York

9. Grosch W (2001) Chemistry III volatile compounds. In: Coffee: Recent Developments. Blackwell Science, London

10. Semmelroch P, Grosch W (1996) Studies on character impact odorants of coffee brews. J Agric Food Chem 44:537-543

11. Mayer F, Czerny M, Grosch W (2000) Sensory study of the character impact aroma compounds of a coffee beverage. Eur Food Res Technol 211:272-276

12. Maier HG, Balcke C, Thies F-C (1983) Die Säuren des Kaffees. VI. Abhängigkeit des sauren Geschmacks von pH-Wert und Säuregrad. Lebensmittelchem Gericht Chem 37:81-83

13. Homma S (2001) Chemistry II: non-volatile compounds, part II. In Coffee: Recent Developments. Blackwell Science, London

14. Clifford MN (1979) Chlorogenic acids -their complex nature and routine determination in coffee beans. Food Chem 4:63-71

15. Moon JK, Yoo HS, Shibamoto T (2009) Role of roasting conditions in the level of chlorogenic acid content in coffee beans: correlation with coffee acidity. J Agric Food Chem 57: 5365-5369

16. Perrone D, Donangelo R, Donangelo CM, Farah A (2010) Modeling weight loss and chlorogenic acids content in coffee during roasting. J Agric Food Chem 58:12238-12243

17. Charles-Bernard M, Kraehenbuehl K, Rytz A, Roberts DD (2005) Interactions between volatile and nonvolatile coffee components. 1. Screening of nonvolatile components. J Agric Food Chem 53: $4117-4125$

18. Fujioka K, Shibamoto T (2006) Quantitation of volatiles and nonvolatile acids in an extract from coffee beverages: correlation with antioxidant activity. J Agric Food Chem 54:6054-6058

19. Clifford MN, Ohiokpehai O (1983) Coffee astringency. Anal Proceed 20:83-86

20. Schwarz B, Hofmann T (2008) Is there a direct relationship between oral astringency and human salivary protein binding? Eur Food Res Technol 227:1693-1698

21. Conversion of Refractive Index and Brix. http://www. jencointernational.com/brix_convert.htm (20-4-2010)

22. Blank I, Sen A, Grosch W (1992) Potent odorants of the roasted powder and brew of arabica coffee. Z Lebensm Unters Forsch 195:239-245

23. Mayer F, Grosch W (2001) Aroma simulation on the basis of the odourant composition of roasted coffee headspace. FFJ 16: 180-190 
24. Blank I, Sen A, Grosch W (1992) Aroma impact compounds of arabica and robusta coffees. Qualitative and quantitative investigations. ASIC-14eme Colloque Scientifique International sur le Café, ASIC, Paris, pp 117-129

25. Deibler KD, Acree TE, Lavin EH (1998) Aroma analysis of coffee brew by gas chromatography-olfactometry. Food flavors: formation, analysis and packaging influences, Contis ET, 69-78

26. Semmelroch P, Grosch W (1995) Analysis of roasted coffee powders and brews by gas chromatography-olfactometry of headspace samples. Lebensm Wiss u Technol 28:310-313

27. Czerny M, Mayer F, Grosch W (1999) Sensory study on the character impact odorants of roasted Arabica coffee. J Agric Food Chem 47:695-699

28. Grosch W (1995) Instrumental and sensory analysis of coffee volatiles. ASIC-16eme Colloque Scientifique International sur le Café, ASIC, Paris, pp 147-156

29. Grosch W (1996) Warum riecht Kaffee so gut? Chem unserer Zeit 30:126-133

30. Bundesamt für Gesundheit (2000) 269.1 Bestimmung des Fettgehalts und der Fettsäurezusammensetzung mittels direkter Umesterung im Lebensmittel. Schweizerisches Lebensmittelbuch

31. Speer K, Kölling-Speer I (2006) The lipid fraction of the coffee bean. Braz J Plant Physiol 18:201-216

32. Speer K, Kölling-Speer I (2001) Chemistry I: non-volatile compounds: lipids. In: Coffee Recent Developments. Blackwell Science, London

33. Ratnayake WMN, Hollywood R, O'Grady E, Stavric B (1993) Lipid content and composition of coffee brews prepared by different methods. Food Chem Toxic 31:263-269

34. Verardo G, Cecconi F, Geatti P, Giumanini AG (2002) New procedures for determination of acids in coffee extracts, and observations on the development of acidity upon ageing. Anal Bioanal Chem 374:879-885

35. Fujioka K, Shibamoto T (2008) Chlorogenic acid and caffeine contents in various commercial brewed coffees. Food Chem 106:217-221

36. Perez-Martínez M, Caemmerer B, Paz de Peña M, Cid C, Kroh LW (2010) Influence of brewing method and acidity regulators on the antioxidant capacity of coffee brews. J Agric Food Chem 58: 2958-2965

37. Ludwig IA, Sanchez L, Caemmerer B, Kroh LW, Paz de Peña M, Cid C (2012) Extraction of coffee antioxidants: impact of brewing time and method. Food Res Int 48:57-64

38. Speer K, Hruschka A, Kurzrock T, Kölling-Speer I (2000) Diterpenes in coffee caffeinated beverages. American Chemical Society, Washington

39. Jham GN, Berhow MA, Manthey LK, Palmquist DA, Vaughn SF (2008) The use of fatty acid profile as a potential marker for Brazilian coffee (Coffea arabica L.) for corn adulteration. J Braz Chem Soc 19:1462-1467

40. Martín MJ, Pablos F, González AG, Valdenebro MS, LeónCamacho M (2001) Fatty acid profiles as discriminant parameters for coffee varieties differentiation. Talanta 54:291-297

41. Carisano A, Gariboldi L (1964) Gaschromatographic examination of the fatty acids of coffee oil. J Sci Food Agric 15: 619-622

42. Rodrigues CI, Marta L, Maia R, Miranda M, Ribeirinho M, Maguas C (2007) Application of solid-phase extraction to brewed coffee caffeine and organic acid determination by UV/HPLC. J Food Compos Anal 20:440-448

43. Crozier TWM, Stalmach A, Lean MEJ, Crozier A (2012) Espresso coffees, caffeine and chlorogenic acid intake: potential health implications. Food Funct 3:30-33

44. Lean MEJ, Crozier A (2012) Coffee, caffeine and health: what's in your cup? Maturitas 72:171-172
45. Balakrishnan Nair R, Viraktamath CS, Balachandran A, Natarajan CP, Bhatia DS (1961) Studies on extraction of coffee by pressure extractors. Food Science (Mysore) 10:86-88

46. Rocha S, Maeztu L, Barros A, Cid C, Coimbra MA (2004) Screening and distinction of coffee brews based on headspace solid phase microextraction/gas chromatography/principal component analysis. J Sci Food Agric 84:43-51

47. Zahm A, Speer K (2010) Coffee aroma-influence of the brewing method and the used coffee. ASIC-23rd Colloque Scientifique International sur le Café, ASIC, Paris, pp 239-243

48. Blumberg S, Frank O, Hofmann T (2010) Quantitative studies on the influence of the bean roasting parameters and hot water percolation on the concentrations of bitter compounds in coffee brew. J Agric Food Chem 58:3720-3728

49. Alves RC, Casal S, Oliveira MB (2010) Tocopherols in coffee brews: influence of coffee species, roast degree and brewing procedure. J Food Compos Anal 23:802-808

50. Alves RC, Costa ASG, Jerez M, Casal S, Sineiro J, Nuñéz MJ, Oliveira B (2010) Antiradical activity, phenolics profile, and hydroxymethylfurfural in espresso coffee: influence of technological factors. J Agric Food Chem 58:12221-12229

51. Alves RC, Soares C, Casal S, Fernandes JO, Oliveira MB (2010) Acrylamide in espresso coffee: influence of species, roast degree and brew length. Food Chem 119:929-934

52. Alves RC, Almeida IMC, Casal S, Oliveira MB (2010) Isoflavones in coffee: influence of species, roast degree, and brewing method. J Agric Food Chem 58:3002-3007

53. Alves RC, Casal S, Oliveira BPP (2007) Factors influencing the norharman and harman contents in espresso coffee. J Agric Food Chem 55:1832-1838

54. Andueza S, Vila MA, Paz de Peña M, Cid C (2007) Influence of coffee/water ratio on the final quality of espresso coffee. J Sci Food Agric 87:586-592

55. Bell LN, Wetzel CR, Grand AN (1996) Caffeine content in coffee as influenced by grinding and brewing techniques. Food Res Int 29:785-789

56. Bunker ML and McWilliams M (1979) Caffeine content of common beverages. J Am Diet Assoc 74:1-28

57. Crozier A, Jaganath IB, Clifford MN (2009) Dietary phenolics: chemistry, bioavailability and effects on health. Nat Prod Rep 26:1001-1043

58. Merritt MC, Proctor BE (1959) Extraction rates for selected components in coffee brew. Food Res 24:735-743

59. Acros Organics (2010) Material Safety Data Sheet: Caffeine

60. Acros Organics (2011) Material Safety Data Sheet: 3-O-Caffeoylquinic acid

61. Zanoni B, Pagliarini E, Peri C (1992) Modelling the aqueous extraction of soluble substances from ground roasted coffee. J Sci Food Agric 58:275-279

62. Andueza S, Paz de Peña M, Cid C (2003) Chemical and sensorial characteristics of espresso coffee as affected by grinding and torrefacto roast. J Agric Food Chem 51:7034-7039

63. Spiro M, Selwood RM (1984) The kinetics and mechanism of caffeine infusion from coffee: the effect of particle size. J Sci Food Agric 35:915-924

64. Maier HG, Balcke C, Thies F-C (1984) Säuren des Kaffees X. Einfluss des bitteren Geschmacks auf den sauren. Dtsch Lebensm-Rundsch 80:367-370

65. Clinton WP, Kaplan JR, and Capasso PJ (1973) Reducing bitterness perception of coffee beverages and products. General Foods Corporation, US 05/151,534, 9-6-1971

66. Fuse T, Kusu F, Takamura K (1997) Determination of acidity of coffee by flow injection analysis with electrochemical detection. J Agric Food Chem 45:2124-2127

67. Clifford MN (1988) What factors determine the intensity of coffee's sensory attributes. Tea \& Coffee Trade Journal 159:8-9 
68. Kampmann B, Maier HG (1982) Säuren des Kaffees. I Chinasäure Z Lebensm Unters Forsch 175:333-336

69. Maier HG (1987) Les acides du café. Café Cacao Thé 31:49-58

70. Scholze A, Maier HG (1984) Säuren des Kaffees VIII. Glykolund Phosphorsäure. Z Lebensm Unters Forsch 178:5-8

71. Maier HG, Engelhardt UH, Scholze A (1984) Säuren des Kaffees IX. Mitt. Zunahme beim Warmhalten des Getränks. Dtsch Lebensm-Rundsch 80:265-268

72. Engelhardt UH, Maier HG (1985) Säuren des Kaffees XII. Anteil einzelner Säuren am sauren Geschmack. Z Lebensm Unters Forsch 181:206-209

73. Engelhardt UH, Maier HG (1985) Säuren des Kaffees XI. Anteil einzelner Säuren an der titrierbaren Gesamtsäure. Z Lebensm Unters Forsch 181:20-23

74. Lugaz O, Pillias AM, Boireau-Ducept N, Faurion A (2005) TimeIntensity evaluation of acid taste in subjects with saliva high flow and low flow rates for acids of various chemical properties. Chem Senses 30:89-103
75. Sivetz M (1972) How acidity affects coffee flavor. Food Technol 26:70-77

76. Frank O, Zehentbauer G, Hofmann T (2006) Bioresponse-guided decomposition of roast coffee beverage and identification of key bitter taste compounds. Eur Food Res Technol 222:492-508

77. Frank O, Blumberg S, Kunert C, Zehentbauer G, Hofmann T (2007) Structure determination and sensory analysis of bittertasting 4-vinylcatechol oligomers and their identification in roasted coffee by means of LC-MS/MS. J Agric Food Chem 55: 1945-1954

78. Kreppenhofer S, Frank O, Hofmann T (2011) Identification of (furan-2-yl) methylated benzene diols and triols as a novel class of bitter compounds in roasted coffee. Food Chem 126:441-449

79. Barron D, Pineau N, Matthey-Doret W, Ali S, Sudre J, Germain JC, Kolodziejczyk E, Pollien P, Labbe D, Jarisch C, Dugas V, Hartmann C, Folmer B (2012) Impact of crema on the aroma release and the in-mouth sensory perception of espresso coffee. Food Funct 3:923-930 